\title{
Reconstructing the Meridional Overturning Circulation from Boundary Densities and the Zonal Wind Stress
}

\author{
J. HIRSCHI \\ School of Ocean and Earth Science, National Oceanography Centre, Southampton, Southampton, United Kingdom \\ J. MAROTZKE \\ Max Planck Institute for Meteorology, Hamburg, Germany
}

(Manuscript received 9 September 2005, in final form 16 June 2006)

\begin{abstract}
Numerical models are used to test whether the meridional overturning circulation (MOC) can be reconstructed from boundary densities and the wind stress. In idealized model setups without topography the strength as well as the temporal and spatial variability of the MOC cell can largely be reproduced from boundary densities and the zonal wind stress. With added slopes along the meridional boundaries, most of the depth-averaged flow is missed and neither strength nor spatial structure of the MOC is well reproduced. However, the temporal evolution of both MOC and its estimate are similar. In an eddy-permitting model with realistic bottom topography the contribution of the depth-averaged meridional flow to the MOC is captured at some places while it is missed at others. Nevertheless, boundary densities and the zonal wind stress allow the leading modes of the temporal and spatial MOC variability to be reproduced. On seasonal time scales most of the MOC variability is due to the wind stress but changes in the boundary density affect the MOC as well. On interannual time scales the MOC variability largely reflects changes in the boundary density. Generally, the MOC reconstructions are accurate when bottom velocities are small, an assumption made in the reconstruction approach. The results are relevant for estimates of both the modern and the past MOC. In the real ocean, boundary densities can be obtained from measurements of temperature, conductivity, and pressure in the water column, whereas past seawater densities have left their imprint in sea sediments.
\end{abstract}

\section{Introduction}

The meridional overturning circulation (MOC) advects warm and salty surface waters to high northern latitudes, where cooling increases sea surface density. Eventually, surface waters sink and flow southward as a deep western boundary current (Dickson and Brown 1994). This circulation transports about $1 \mathrm{PW}(1 \mathrm{PW} \equiv$ $10^{15} \mathrm{~W}$ ) of heat to the North Atlantic Ocean, which is approximately equivalent to the northward energy transport occurring in the atmosphere over the North Atlantic area (Trenberth and Solomon 1994; Trenberth and Caron 2001). The predominantly westerly winds at

Corresponding author address: J. Hirschi, School of Ocean and Earth Science, National Oceanography Centre, Southampton, University of Southampton, Waterfront Campus, European Way, Southampton SO14 3ZH, United Kingdom.

E-mail: jjmh@noc.soton.ac.uk northern midlatitudes carry large parts of this heat toward Europe thus contributing to its mild climate.

One fundamental issue is the understanding of the variability of the MOC and of the related heat transport. Palaeoclimatic archives suggest that in the past the thermohaline circulation has undergone large changes (Heinrich 1988; Dansgaard et al. 1993). During the last ice age abrupt changes associated with temperature variations of more than $10^{\circ} \mathrm{C}$ over Greenland were not uncommon (e.g., Lang et al. 1999) and one plausible mechanism is a changing strength of the MOC (e.g., Broecker et al. 1992). Even the relatively stable Holocene shows important variations. Recent ones such as the Little Ice Age occurred in historical times and are, at least partly, documented by instrumental records. The underlying mechanisms and the links with the ocean circulation are still under debate. During the last century, anthropogenic emissions have risen the levels of greenhouse gases to a level unprecedented

DOI: $10.1175 / J P O 3019.1$

(C) 2007 American Meteorological Society 
during the last $500 \mathrm{kyr}$ (Petit et al. 1999) thus raising the question of the future behavior of the MOC.

Different ocean/ocean-atmosphere general circulation models (OGCMs/AOGCMs) have been used to investigate the MOC variability (e.g., Weaver and Sarachik 1991; Häkkinen 1999; Eden and Greatbatch 2003; Delworth et al. 1993; Ganopolski and Rahmstorf 2001; Collins et al. 2001). These studies suggest a wide range of time scales associated with the variability of the MOC and indicate that even without increased greenhouse forcing the MOC exhibits a large "natural" variability. The behavior of the MOC under increased levels of $\mathrm{CO}_{2}$ in the atmosphere has been widely addressed in modeling studies (Cubasch et al. 2001) and most models agree that the MOC changes exceed its natural variability when certain thresholds are reached. The potential instability of the MOC inferred from proxy data for the past and from numerical simulations for the future indicate the importance of knowing the current state of the MOC.

Observation-based estimates of the actual MOC and of related transports are mostly based on hydrographic sections that provide snapshots of the circulation (e.g., Hall and Bryden 1982; Ganachaud and Wunsch 2000). For continuously measuring the MOC, frequent repeat sections would be required. Therefore, the next question is whether the amount of measurements can be reduced without losing the main features of the MOC. Using the density gradient across the Florida Strait obtained from $\delta^{18} \mathrm{O}$ of calcite in foraminifera, LynchStieglitz et al. (1999) inferred the vertical flow structure during the Last Glacial Maximum. The same approach has been suggested to estimate the basinwide flow for past circulations (Lynch-Stieglitz 2001). Model results indicate that based on the knowledge of zonal density gradients obtained from few moorings, the current MOC might be observed continuously across longitude-depth sections in the North Atlantic (Hirschi et al. 2003; Baehr et al. 2004). Results from these papers have been implemented in a real observing system of the Atlantic MOC that was deployed at $26^{\circ} \mathrm{N}$ in 2004 (Marotzke et al. 2002).

A conceptual study of Marotzke (1997) highlighted the relation between the density structure at the western and eastern boundaries of an idealized, purely buoyancy forced ocean model and the MOC strength. The question addressed here is whether this density information combined with the zonal wind stress is enough to infer the strength as well as the temporal and spatial variability of the MOC on a basinwide scale. In contrast to previous studies (Hirschi et al. 2003; Baehr et al. 2004) no attempt is made to optimize an MOC "monitoring" system at particular latitudes in the ocean.
Instead we discuss the quality of estimates of the MOC if the same approach is used for an entire basin. This paper can be considered to be the theoretical underpinning of the experimental design work found in Hirschi et al. (2003) and Baehr et al. (2004).

The paper is organized as follows. Section 2 describes how the MOC is decomposed into the dominant terms that govern its force balance. Section 3 introduces the models and experiments. Results for the MOC estimates are presented in sections 4 and 5. An outlook as well as conclusions are given in sections 6 and 7 .

\section{Method}

The starting point is a decomposition of the MOC similar to the one used in Lee and Marotzke (1998). The MOC $\psi$ is split into three different contributions related to the barotropic (depth averaged) velocities $\bar{v}$ to the geostrophic shear $v_{\mathrm{sh}}$, and to Ekman transports $v_{\mathrm{ek}}$,

$$
\begin{aligned}
\psi\left(z^{\prime}\right)= & \int_{-H}^{z^{\prime}} d z \int_{x_{w}}^{x_{e}} d x \bar{v}+\int_{-H}^{z^{\prime}} d z \int_{x_{w}}^{x_{e}} d x v_{\mathrm{sh}} \\
& +\int_{-H}^{z^{\prime}} d z \int_{x_{w}}^{x_{e}} d x\left(v_{\mathrm{ek}}-\bar{v}_{\mathrm{ek}}\right),
\end{aligned}
$$

where $x_{w}$ and $x_{e}$ are the western and eastern limits of the basin, respectively, and where $-H \leq z^{\prime} \leq 0$.

The method developed here aims to approximate Eq. (1) using only quantities that can be measured in the real ocean. The first right-hand term in Eq. (1) is the most difficult one. It does contribute to the MOC in the presence of topography and is often referred to as the external mode

$$
\psi_{\mathrm{ex}}\left(z^{\prime}\right)=\int_{-H}^{z^{\prime}} d z \int_{x_{w}}^{x_{e}} \bar{v} d x
$$

with

$$
\bar{v}=\frac{1}{H} \int_{-H}^{0} v d z,
$$

where $v$ is the full meridional velocity component. Currently, there is no existing measuring strategy for the depth-averaged (barotropic) flow and for the external mode $\psi_{\mathrm{ex}}$ but as we will show later there are situations where boundary densities allow us to reconstruct the barotropic flow to a large extent.

From the knowledge of the zonal wind stress the Ekman velocity $v_{\mathrm{ek}}$ can be derived from the theoretical relationship

$$
v_{\mathrm{ek}}=-\frac{1}{\rho^{*} f L \Delta z} \int_{x_{w}}^{x_{e}} \tau^{x} d x
$$


where $\rho^{*}, f, L$, and $\tau^{x}$ are a reference density, the Coriolis parameter, the basin width at the surface, and the zonal wind stress, respectively. We assume that the Ekman transport occurs in a layer of thickness $\Delta z$ and is compensated by a barotropic return flow

$$
\bar{v}_{\mathrm{ek}}=-\frac{1}{\rho^{*} f A} \int_{x_{w}}^{x_{e}} \tau^{x} d x,
$$

where $A$ is the total area of the corresponding longitude-depth section of the ocean basin. This approach relies on the assumption that the basinwide density structure cannot adjust to changes in the wind field fast enough to allow for a baroclinic compensation. From $v_{\text {ek }}$ and $\bar{v}_{\text {ek }}$ the Ekman contribution $\psi_{\text {ek }}$ to the MOC is calculated according to

$$
\psi_{\mathrm{ek}}\left(z^{\prime}\right)=\int_{-H}^{z^{\prime}} d z \int_{x_{w}}^{x_{e}}\left(v_{\mathrm{ek}}-\bar{v}_{\mathrm{ek}}\right) d x
$$

which is identical to the third term of the right-hand side of Eq. (1). Equation (6) allows us to isolate an MOC contribution related to the shear due to Ekman transports and that can account for a large fraction of the total MOC (Lee and Marotzke 1998).

The shear component in Eq. (1) is defined as $v_{\mathrm{sh}}=$ $v-\bar{v}-\left(v_{\mathrm{ek}}-\bar{v}_{\mathrm{ek}}\right)$, where $v$ is the full meridional velocity. Since the shear related to the Ekman transport is removed, $v_{\mathrm{sh}}$ reflects the geostrophic shear. According to Marotzke et al. (1999) the geostrophic shear can be obtained from an endpoint method based on the thermal wind balance

$$
f \frac{\partial v}{\partial z}=-\frac{g}{\rho^{*}} \frac{\partial \rho}{\partial x},
$$

where $g$ is the earth's acceleration. Zonally integrating Eq. (7) yields

$$
\int_{x_{w}}^{x_{e}} \frac{\partial v}{\partial z} d x=-\frac{g}{\rho^{*} f}\left(\rho_{e}-\rho_{w}\right) .
$$

According to Eq. (8) knowing the seawater densities at the eastern $\left(\rho_{e}\right)$ and western $\left(\rho_{w}\right)$ boundary is sufficient to capture the zonally integrated shear.

For the next step we assume that bottom velocities vanish. This condition is relaxed later on, to ensure mass balance. However, in the final reconstruction bottom velocities are implicitly assumed to be small (cf. Baehr et al. 2004). Dividing the right-hand side of Eq. (8) by the basin width $L(z)$ and integrating vertically from bottom to $z^{\prime}$ yields a meridional velocity component:

$$
\tilde{v}\left(x, z^{\prime}\right)=-\frac{g}{\rho^{* f}} \int_{-H}^{z^{\prime}} \frac{1}{L(z)}\left(\rho_{e}-\rho_{w}\right) d z .
$$

The motivation for choosing a level of no motion at the bottom for $\tilde{v}\left(x, z^{\prime}\right)$ is that we want to use an approach that can be used at all latitudes. A level of no motion at a fixed depth is problematic since the level of no motion is not constant throughout the ocean. Assuming that the thermal wind captures the shear of the meridional flow and that the velocities at the ocean bottom are zero or close to zero then $\tilde{v}$ is a good approximation of the velocity field. Consider an example with northward flow in the upper $1000 \mathrm{~m}$ and a return flow between depths of 1000-3000 $\mathrm{m}$ and where the total ocean depth is $4000 \mathrm{~m}$ (zero velocity at the bottom). Assuming zero velocity at the bottom is equivalent to assuming it at $1000 \mathrm{~m}$, which would be the correct choice. Of course the bottom velocities are not always zero (e.g., Lee et al. 1996) and the assumption of vanishing velocity at the bottom can lead to an inaccurate representation of the velocity (Baehr et al. 2004).

In general the depth average of $\tilde{v}$ is not zero and $\tilde{v}$ contains depth-dependent (baroclinic) as well as barotropic elements. To make it comparable to $v_{\mathrm{sh}}$ in Eq. (1) the depth average

$$
\bar{v}^{\prime}(x)=\frac{1}{H(x)} \int_{-H(x)}^{0} \tilde{v}(z, x) d z
$$

has to be removed.

The problem with removing the depth average from $\tilde{v}$ is that valuable information is lost: $\tilde{v}$ does contain a barotropic component that might be useful to estimate the external mode. As mentioned above at places where the bottom velocities are close to zero the velocity $\tilde{v}$ is comparable to the full velocity (except for the Ekman transport at the surface). Therefore, a large fraction of the barotropic flow and of the external mode might be contained in $\tilde{v}$ at locations where the bottom velocities are zero or close to zero along sloping sidewalls.

To test this assumption $\tilde{v}$ is used to compute a streamfunction:

$$
\tilde{\psi}\left(z^{\prime}\right)=\int_{x_{w}}^{x_{e}} d x \int_{-H}^{z^{\prime}} \tilde{v} d z .
$$

In general $\tilde{\psi}$ does not fulfill the condition $\tilde{\psi}\left(z^{\prime}\right)=0$, $z^{\prime}=0,-H$. We introduce a correction

$$
\hat{v}=\psi(0) / A,
$$

for $\tilde{v}$, which is obtained by dividing the transport imbalance $\psi(0)$ across a longitude-depth section by the section area $A$. This correction fulfills the mass conservation without affecting the vertical shear estimated from Eq. (8). Note that the Atlantic and Pacific Ocean 


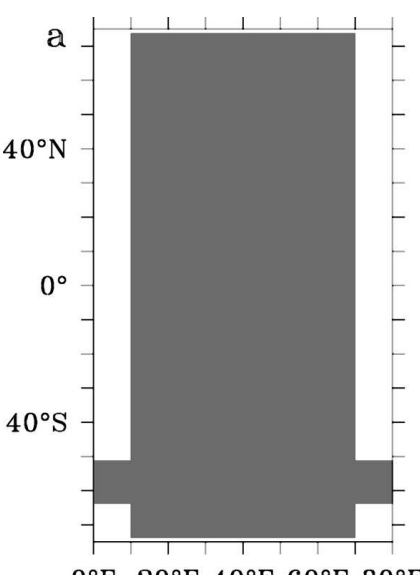

$0^{\circ} \mathrm{E} 20^{\circ} \mathrm{E} 40^{\circ} \mathrm{E} 60^{\circ} \mathrm{E} 80^{\circ} \mathrm{E}$
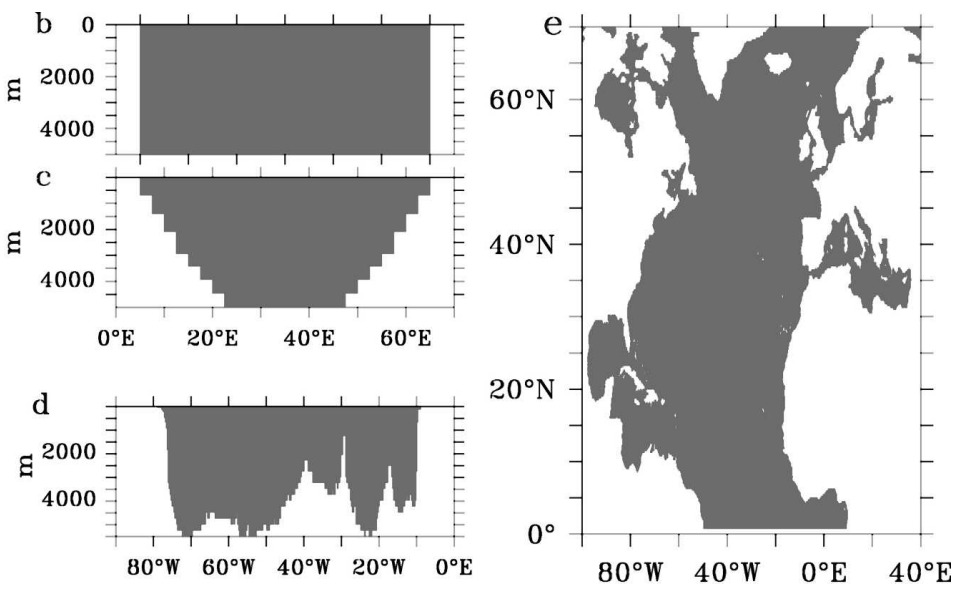

FIG. 1. (a)-(c) Model geometries for the idealized runs (b) without and (c) with topography. (d), (e) Eddypermitting model (OCCAM). In the present study we only consider a North Atlantic domain extending from the equator to $70^{\circ} \mathrm{N}$. As an illustration (d) shows the topography at $40^{\circ} \mathrm{N}$.

basins are not closed in the north and water can leave/ enter via the Bering Strait. However, this exchange only being in the order of $1 \mathrm{~Sv}\left(1 \mathrm{~Sv} \equiv 10^{6} \mathrm{~m}^{3} \mathrm{~s}^{-1}\right.$; Coachman and Aagaard 1988), it is not considered here.

With the corrections for $\tilde{v}$ defined by Eqs. (12) and (10) we can calculate two streamfunctions

$$
\begin{aligned}
& \psi_{\mathrm{tw}_{1}}\left(z^{\prime}\right)=\int_{x_{w}}^{x_{e}} d x \int_{-H}^{z^{\prime}}(\tilde{v}-\hat{v}) d z \quad \text { and } \\
& \psi_{\mathrm{tw}_{2}}\left(z^{\prime}\right)=\int_{x_{w}}^{x_{e}} d x \int_{-H}^{z^{\prime}}\left(\tilde{v}-\bar{v}^{\prime}\right) d z,
\end{aligned}
$$

where both $\psi_{\mathrm{tw}_{1}}$ and $\psi_{\mathrm{tw}_{2}}$ fulfill the condition $\psi_{\mathrm{tw}}\left(z^{\prime}\right)=$ $0, z^{\prime}=0,-H$. The corrections for the mass conservation mean that the bottom velocities no longer vanish. However, with Eq. (12) they remain small since the mass imbalance is divided by the entire cross-section area. Equation (14) is equivalent to the second term on the right-hand side of Eq. (1). The streamfunction described in Eq. (13) does contain a barotropic contribution and in the following we assume that it is representative of the sum of the first two terms on the righthand side of Eq. (1). Note that without topography both streamfunctions $\psi_{\mathrm{tw}_{1}}$ and $\psi_{\mathrm{tw}_{2}}$ are identical (see appendix A). It is also worth mentioning that $\psi_{\mathrm{tw}_{1}}$ is equivalent to an estimate of the thermal wind contribution based on vertical profiles of density placed across longitude-depth sections as used in Hirschi et al. (2003) and Baehr et al. (2004) (see appendix B).

The total MOC can now be written as

$$
\begin{aligned}
& \psi_{1}=\psi_{\mathrm{tw}_{1}}+\psi_{\mathrm{ek}} \quad \text { or } \\
& \psi_{2}=\psi_{\mathrm{tw}_{2}}+\psi_{\mathrm{ek}}+\psi_{\mathrm{ex}} .
\end{aligned}
$$

The motivation for using $\psi_{1}$ lies in the fact that it is only based on quantities that can be estimated from measurements of the surface wind stress and of seawater density along the continental slopes. Using $\psi_{2}$ is more likely to represent the MOC accurately, however, this requires the knowledge of the barotropic velocity field for which no obvious measuring strategy currently exists.

\section{Models and experiments}

Three different model topographies are used: a flatbottomed rectangular basin, a rectangular basin with sloping sidewalls, and an eddy-permitting model with realistic topography. Using these model setups allows us to estimate how the quality of MOC reconstructions is affected by gradually increasing the complexity of the models.

\section{a. Idealized models}

The simulations using idealized geometries are performed with the Massachusetts Institute of Technology (MIT) OGCM (Marshall et al. 1997). The model domain consists of a $60^{\circ}$ wide rectangular basin extending from $75^{\circ} \mathrm{S}$ to $75^{\circ} \mathrm{N}$ (Fig. 1a). Between $65^{\circ}$ and $50^{\circ} \mathrm{S}$ the basin is crossed by an Antarctic Circumpolar Current (ACC) channel. The horizontal resolution is $2.5^{\circ}$ in both longitude and latitude and the vertical is divided into 19 layers with thickness increasing exponentially from $30 \mathrm{~m}$ at the surface to more than $500 \mathrm{~m}$ at the bottom. The maximum depth is set to $5000 \mathrm{~m}$. As shown in Figs. 1b,c this model is set up in two different configurations with a flat bottom or sloping sidewalls 
TABLE 1. Configurations for experiments A-D.

\begin{tabular}{clccc}
\hline \hline Name & Model & Topography & Wind & Perturbation \\
\hline A & MIT & No & No & Yes \\
B & MIT & No & Yes & Yes \\
C & MIT & Yes & Yes & Yes \\
D & OCCAM & Yes & Yes & No \\
\hline
\end{tabular}

along the meridional boundaries. The horizontal viscosity and diffusivity coefficients are set to $2.5 \times 10^{5} \mathrm{~m}^{2} \mathrm{~s}^{-1}$ and $2.5 \times 10^{3} \mathrm{~m}^{2} \mathrm{~s}^{-1}$, respectively. Values for the vertical viscosity and diffusivity are set to 20 and $1 \mathrm{~cm}^{2} \mathrm{~s}^{-1}$, respectively. Both models are forced with idealized zonally constant forcing profiles for the zonal wind, the temperature, and the salinity similar to the ones used in Hirschi and Stocker (2002).

\section{b. Eddy-permitting $O G C M$}

The model used here is a $14^{\circ}$ version of the Ocean Circulation and Climate Advanced Modeling Project (OCCAM) described in Marsh et al. (2005a,b). OCCAM is a global general circulation model with realistic topography, and because of its relatively high resolution it is eddy permitting (i.e., eddies are simulated, but their dynamics is poorly resolved). The vertical is divided into 66 levels with thicknesses ranging from $5 \mathrm{~m}$ at the surface to $207 \mathrm{~m}$ at the bottom. The surface forcing consists of 6-hourly fluxes from the National Centers for Environmental Prediction (NCEP) for wind, heat, and evaporation minus precipitation $(E-P$; Kalnay et al. 1996). For the sea surface salinity there is an additional restoring term to monthly values of Levitus and Boyer (1994). The model simulates the global ocean circulation for the years 1985-2003. In the present study we only use a North Atlantic domain of OCCAM extending from the equator to $70^{\circ} \mathrm{N}$ (Fig. 1e).

\section{c. Experiments}

To investigate the relative importance of each contribution in the different model configurations we set up four experiments, which are summarized in Table 1. Experiment A is purely buoyancy forced and has no topography and is therefore suited to test if the thermal wind relation reproduces the vertical velocity shear. The wind stress in experiment B leads to Ekman transports that are not linked to zonal density gradients. In experiment $\mathrm{C}$ the addition of topography means that barotropic contributions (external mode) no longer vanish. A gradual slope was chosen in order to ensure pronounced topographic effects. Note that in the real ocean, the continental slopes are generally steeper.
Last, experiment $\mathrm{D}$ allows us to investigate which terms are dominant for a realistic model configuration.

Starting from rest, the idealized models are integrated under restoring boundary conditions for temperature and salinity until a quasi equilibrium is reached after 4000 model years. At the end of this first phase the freshwater fluxes are diagnosed and both model versions are further integrated for $1000 \mathrm{yr}$ under mixed boundary conditions (restoring for temperature, temporally constant diagnosed freshwater flux). To investigate the quality of MOC reconstructions during transient phases, a freshwater discharge is applied at high northern latitudes thus inducing a temporary change in the strength the MOC. The perturbation consists of a short $(10 \mathrm{yr})$ freshwater discharge of $0.2 \mathrm{~Sv}$ evenly spread across the whole basin width at $62.5^{\circ} \mathrm{N}$.

The freshwater discharge occurs between years 10 and 20 of the last $100 \mathrm{yr}$ of the model runs.

The OCCAM integration simulates the global ocean circulation between the years 1985 and 2003. The main run is preceded by a 4 -yr spinup phase during which the model uses the forcing of the years 1985-88. Because of the relatively short integration time, the circulation in OCCAM has not reached equilibrium yet. Nevertheless, the circulation does not show any major drifts. The temporally variable surface forcing (wind, heat, $E-P$ ) ensures a temporal and spatial variability of the circulation (see section 5). Details about the circulation in OCCAM can be found in Marsh et al. (2005a,b).

\section{Meridional mass transports: Steady states}

Here we present and discuss estimates of the MOC obtained using the method described in section 2. The MOC circulations considered here are steady states for experiments A-C and a mean for the years 1985-2003 for experiment $\mathrm{D}$.

\section{a. Idealized cases}

In experiments $\mathrm{A}$ and $\mathrm{B}$ the MOC consists of one clockwise overturning cell with sinking of water masses at high northern latitudes and upwelling south of $50^{\circ} \mathrm{N}$ (Figs. 2a and 3a). The maximum MOC is reached around $55^{\circ} \mathrm{N}$ and at $2000-\mathrm{m}$ depth with values of 22 and $24 \mathrm{~Sv}$ for experiments A and B, respectively. For both circulations $10 \mathrm{~Sv}$ of deep water are exported from the northern to the Southern Hemisphere. The action of the wind in experiment $B$ is reflected by the presence of equatorial and subtropical Ekman overturning cells in both hemispheres. The clockwise northern equatorial and southern midlatitude Ekman cells merge with the main MOC cell while the southern equatorial and 

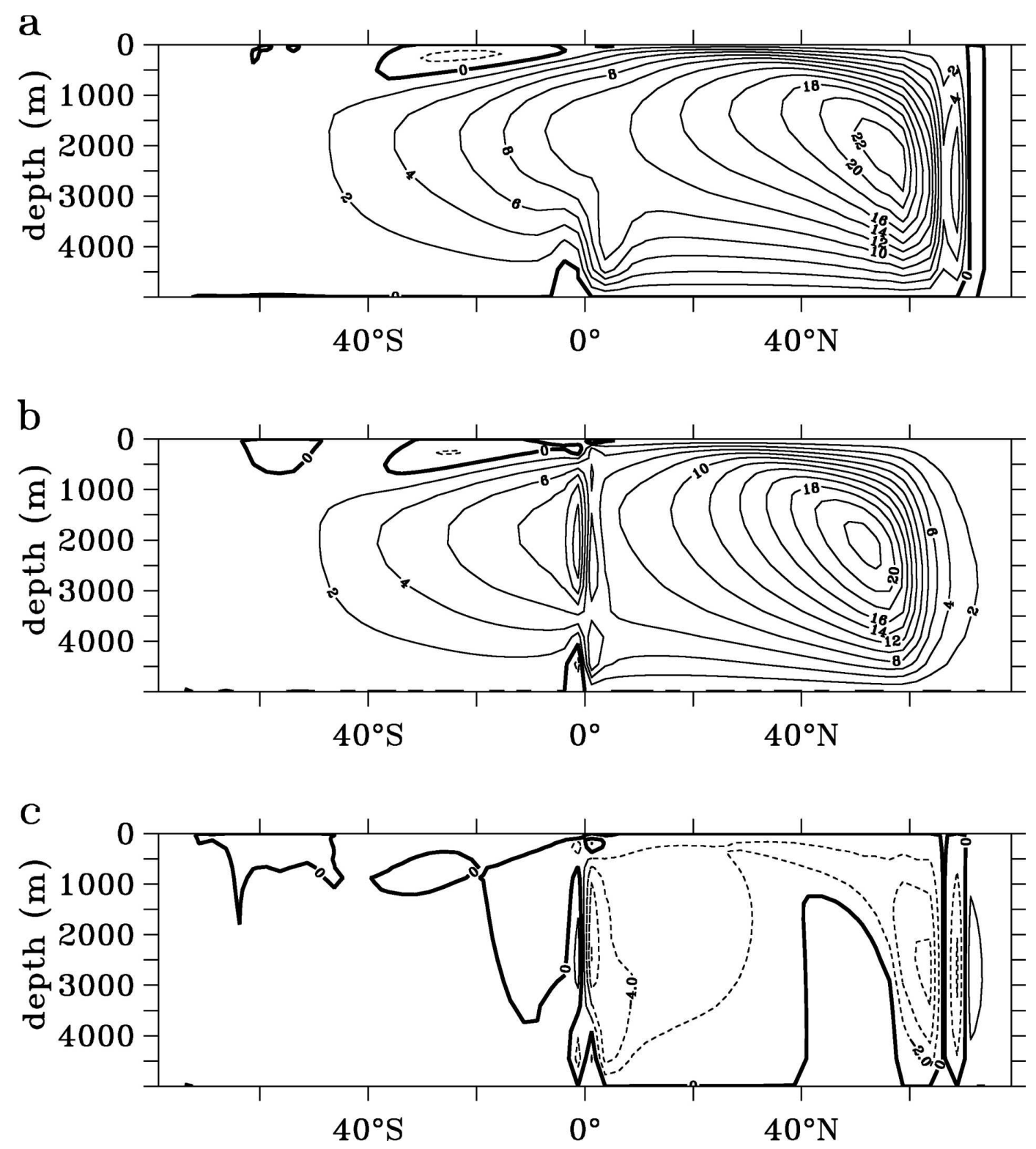

FIG. 2. Reconstruction of MOC for experiment A. (a) MOC based on meridional velocity field. (b) Reconstruction based on the thermal wind contribution. (c) Difference between the reconstruction and the MOC. Units are Sverdrups $\left(1 \mathrm{~Sv} \equiv 10^{6} \mathrm{~m}^{3} \mathrm{~s}^{-1}\right)$, and the contour interval $(\mathrm{CI})=2 \mathrm{~Sv}$.

northern midlatitude cells are visible as counterclockwise features.

For experiment $A$ the meridional extent and strength of the reconstructed overturning cell are similar to what is seen for the MOC (Fig. 2b). Shortcomings are most pronounced north of $60^{\circ} \mathrm{N}$ where the reconstruction is weaker by up to $6 \mathrm{~Sv}$ (Fig. 2c). Between the high northern latitudes and the equator the differences are small with maximum values of about $2 \mathrm{~Sv}$. At the equator the differences reflect the limitations of the thermal wind balance due to the division by the Coriolis parameter $f$ in Eq. (7).
In experiment $\mathrm{B}$ the reconstruction has too much upwelling between $55^{\circ}$ and $35^{\circ} \mathrm{N}$, which results in lower values between northern midlatitudes and the equatorial region (Figs. 3b,c). Equation (1) allows us to reproduce the Ekman cells that are visible in the reconstruction as (anti)clockwise cells at the surface. The largest differences between the reconstruction and the MOC occur between $20^{\circ}$ and $30^{\circ} \mathrm{N}$ and north of $60^{\circ} \mathrm{N}$.

In experiments $\mathrm{A}$ and $\mathrm{B}$ the differences between the MOC and its reconstruction are largely negative indicating that at places the shear of the meridional flow is underestimated by the thermal wind. The reason for 

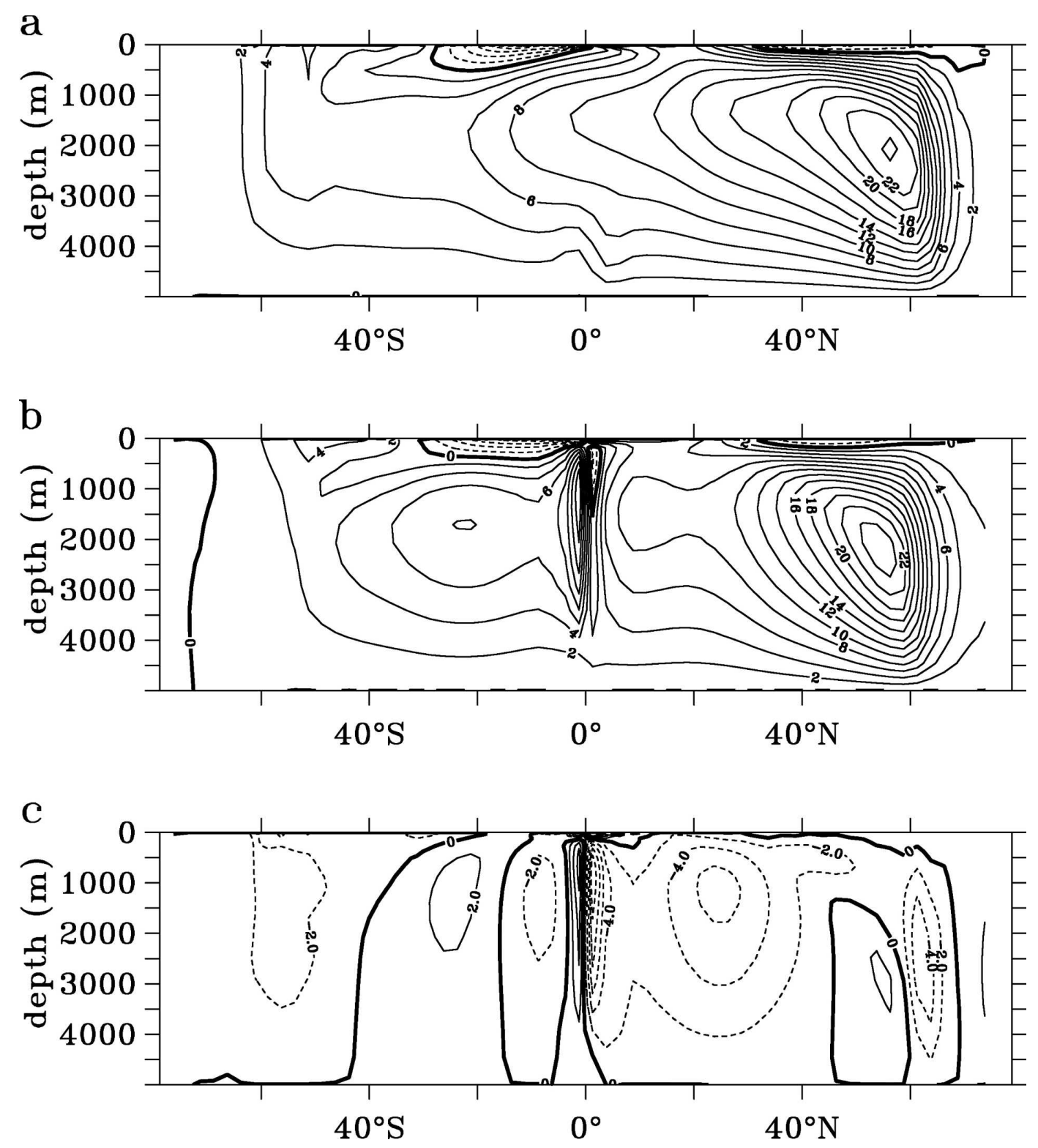

FIG. 3. Reconstruction of MOC for experiment B. (a) MOC based on meridional velocity field. (b) Sum of contributions related to the thermal wind and to the Ekman transport. (c) Difference between the reconstruction and the MOC. Units are Sverdrups, and the $\mathrm{CI}=2 \mathrm{~Sv}$.

this is not fully understood yet but in the following we give some elements of explanation. The latitudes between $60^{\circ}$ and $65^{\circ} \mathrm{N}$ are adjacent to the deep convection area found in the northernmost latitudes. Between the northern high and midlatitudes there is a negative slope for the sea surface height $\eta$ (i.e., $\partial \eta / \partial y<0$; not shown). According to geostrophy the sloping in $\eta$ has to be balanced by an eastward flow (Figs. 4a,b). This current is the extension of the western boundary current that separates from the western boundary between $40^{\circ}$ and $60^{\circ} \mathrm{N}$ and when it approaches the eastern boundary the horizontal mass convergence leads to an increase in sea surface height $\eta(\partial \eta / \partial x>0)$ at the eastern wall (Figs. 4a,b). According to geostrophy the slope in $\eta$ must be balanced by a northward flow. In experiment B large differences occur between $20^{\circ}$ and $40^{\circ} \mathrm{N}$ where the intensifying of the wind-driven gyre at the western boundary coincides with a local maximum of the sea surface height centered at $30^{\circ} \mathrm{N}, 17^{\circ} \mathrm{E}$, which reflects a wind-driven horizontal convergence of mass (Fig. 4b). Even in an ocean with constant seawater density, the wind stress would lead to the formation of gyres and 

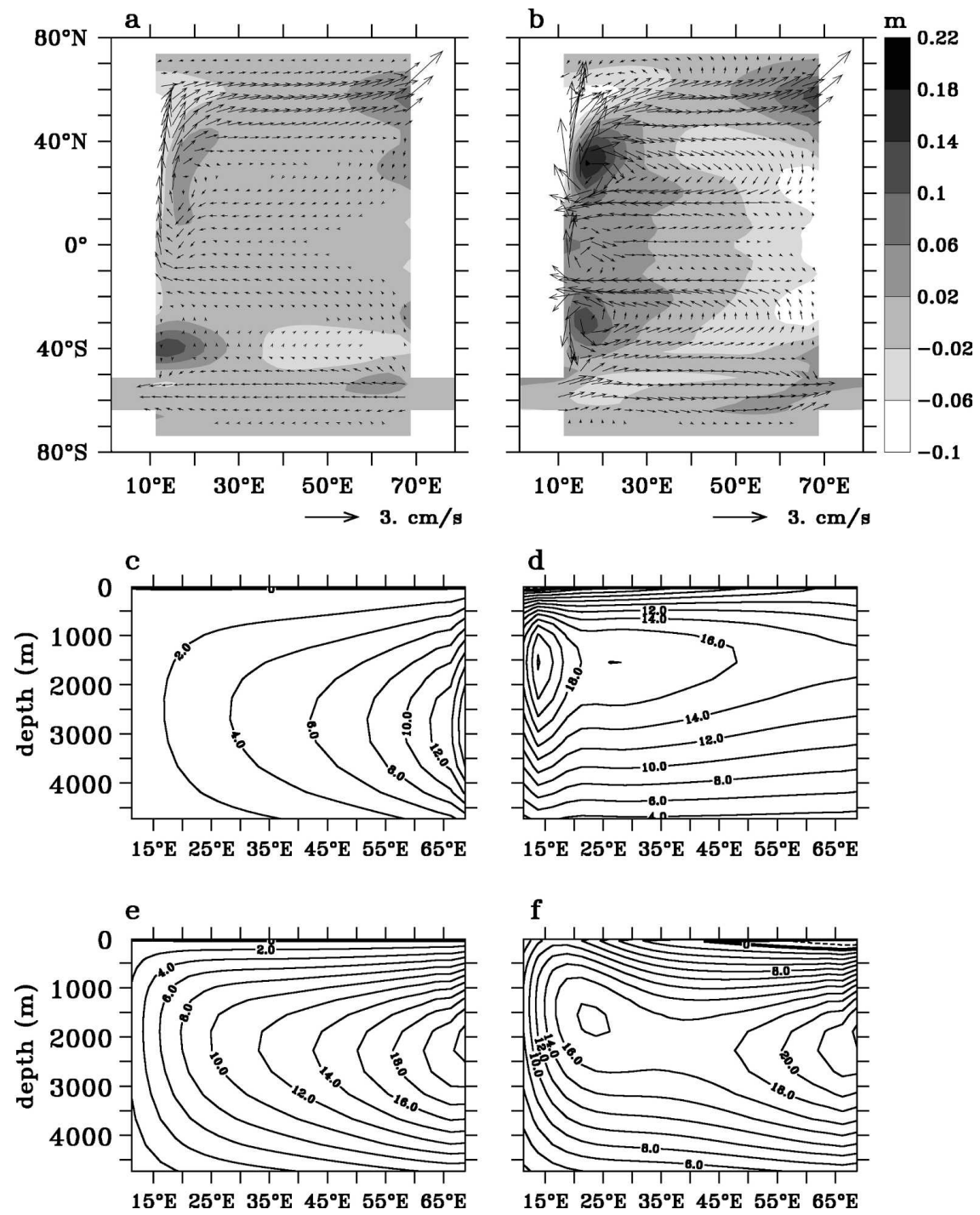

FIG. 4. (a), (b) Circulation averaged over the top $1000 \mathrm{~m}$ (vectors) and zonal anomalies for the sea surface height (shading) for experiments (a) A and (b) B. (c) Cumulative transport at $63^{\circ} \mathrm{N}$ for experiment A. (d) Cumulative transport at $21^{\circ} \mathrm{N}$ for experiment B. (e) Cumulative transport at $55^{\circ} \mathrm{N}$ for experiment A. (f) Cumulative transport at $55^{\circ} \mathrm{N}$ for experiment $\mathrm{B}$. The $\mathrm{CI}=2 \mathrm{~Sv}$ for $(\mathrm{c})-(\mathrm{f})$.

anomalies of the sea surface height that are not related to the density structure of the water column. As a consequence, the density field used to compute the thermal wind contribution in experiment $\mathrm{B}$ misses a substantial fraction of the western boundary current that forms the northward flowing branch of the subtropical gyre.

For experiments $\mathrm{A}$ and $\mathrm{B}$ the differences are generally smaller than $2 \mathrm{~Sv}$ between $40^{\circ}$ and $60^{\circ} \mathrm{N}$. At those latitudes the western boundary current gradually separates from the boundary and starts to flow eastward (Figs. 4a,b). There is no horizontal convergence of mass that leads to a geostrophically balanced flow that is not reflected in the seawater densities.
Next we examine the zonal structure of the meridional flow at latitudes where large or small differences are found between the MOC and its reconstruction (Figs. 4c-f). We consider the cumulative meridional transport

$$
\Psi_{\mathrm{cum}}\left(x^{\prime}, z^{\prime}\right)=\int_{x_{w}}^{x^{\prime}} d x \int_{-H}^{z^{\prime}} v d z
$$

where $x_{w} \leq x^{\prime} \leq x_{e}$.

For experiment $\mathrm{A}, \Psi_{\text {cum }}$ at $63^{\circ} \mathrm{N}$ shows a gradual increase of the cumulative northward flow from 0 to 10 Sv between the western boundary and $55^{\circ} \mathrm{E}$ (Fig. 4c). Tightening isolines between $55^{\circ} \mathrm{E}$ and the eastern 
boundary indicate the presence of an eastern boundary current contributing $8 \mathrm{~Sv}$ to the total MOC. This meridional transport is related to the eastward flow escaping northward previously described. Below 25003000-m depth the northward transport is compensated by a southward return flow. As for the northward flow there is a strengthening of the return flow close to the eastern boundary.

For experiment B, the structure of the cumulative transport at high northern latitudes is similar to that of experiment A (not shown). Instead we look at $21^{\circ} \mathrm{N}$, a latitude representative of the differences seen between the MOC and the reconstruction at midlatitudes (Fig. 4d). The zonal structure is different from what is seen at high northern latitudes: here all northward transport occurs close to the western boundary and the maximum northward transport is reached at $13^{\circ} \mathrm{E}$ at a depth of $1500 \mathrm{~m}$. Most of this northward flow is compensated by a deep western boundary current indicated by the isolines of the cumulative transport west of $13^{\circ} \mathrm{W}$ as well as by a return flow related to the gyre circulation visible as tight isolines between $13^{\circ}$ and $20^{\circ} \mathrm{E}$ and $1500-\mathrm{m}$ depth. West of $20^{\circ} \mathrm{E}$ there is a weak gradual southward flow of $4 \mathrm{~Sv}$ (1500-m depth).

At $55^{\circ} \mathrm{N}$ the difference between the MOC and the reconstruction is small for experiments A and B (Figs. $4 \mathrm{e}, \mathrm{f})$. In experiment $\mathrm{A}$, the cumulative transport indicates a gradual basinwide meridional flow (Fig. 4e). Above a depth of $2000 \mathrm{~m}$ there is a northward flow that is compensated below that depth. No tightening of the isolines indicates a strengthening of the flow close to the boundaries. A similar picture holds true for experiment B even if here the zonal structure indicates stronger flows in the western and eastern parts of the basin and virtually no flow in the midbasin. However, when compared with the flow pattern illustrated in Figs. 4c,d the eastern and western currents are much broader with a width of about $15^{\circ}$.

With a maximum value of $16 \mathrm{~Sv}$ the MOC is weaker in experiment $\mathrm{C}$ than in the previous cases (Fig. 5a). There is less upwelling at northern midlatitudes and despite the weaker maximum MOC the same amount of deep water $(10 \mathrm{~Sv})$ is exported to the Southern Hemisphere. The wind-driven Ekman cells can be distinguished as shallow (anti)clockwise cells in the surface ocean. Using all components Eq. (16) leads to a good estimate of the MOC (Fig. 5b), whereas Eq. (15) cannot reproduce the MOC cell (Fig. 5c).

If the MOC is calculated according to Eq. (16) the largest differences of $2 \mathrm{~Sv}$ occur between $20^{\circ}-40^{\circ} \mathrm{N}$ and $20^{\circ}-40^{\circ} \mathrm{S}$, respectively (Fig. 6a). As before, the shortcomings seen close to the equator are due to the division by the Coriolis parameter. The small differences are not surprising: using the external mode means that we rely less heavily on the thermal wind and that we introduce the exact barotropic velocities in the calculation of meridional mass transports.

The difference between the estimate based on Eq. (15) and the MOC shows an anticlockwise cell with a value of $14 \mathrm{~Sv}$ between $20^{\circ}$ and $30^{\circ} \mathrm{N}$ where no northward transport is reconstructed (Fig. 6b). The contribution of the depth-averaged velocities (external mode) is essentially the negative image of the error in the reconstruction (Figs. 6b,c). The main reason for the failure to reproduce the depth-averaged velocity is that large velocities are found at the margins. Therefore, assuming the level of no motion to be at the bottom introduces an error in the depth-averaged velocities (Baehr et al. 2004).

\section{b. Realistic model geometry}

When compared with experiments $\mathrm{A}-\mathrm{C}$ the MOC cell is shallower, and the maximum value of $18 \mathrm{~Sv}$ is reached at a depth of $1000 \mathrm{~m}$ (Fig. 7a). This value remains constant between $45^{\circ}$ and $25^{\circ} \mathrm{N}$ and about $14 \mathrm{~Sv}$ of North Atlantic Deep Water (NADW) are exported to the Southern Hemisphere. Using Eq. (16) leads to a good estimate of the MOC (Fig. 7b) although there is a slight overestimation of the MOC strength especially south of $25^{\circ} \mathrm{N}$ and north of $45^{\circ} \mathrm{N}$. With Eq. (15) the reconstruction is less accurate, however, major features such as the single cell structure and the depth where maximum transports occur are reproduced (Fig. 7c). North of $35^{\circ} \mathrm{N}$ the values of both reconstructions are similar. South of that latitude the reconstruction based on Eq. (15) is noisier than the estimate based on Eq. (16).

The Ekman contribution (Fig. 8a) shows two distinct cells with maximum/minimum values of 14 and $-2 \mathrm{~Sv}$ at $13^{\circ}$ and $50^{\circ} \mathrm{N}$, respectively. The assumption is made that the total Ekman transport occurs in the upper $30 \mathrm{~m}$ of the model. Because of the barotropic compensation of the surface flow [Eq. (6)] the Ekman cells reach to great depths. For high-frequency variability a barotropic return flow may reflect the return path of the surface flow (Lee and Marotzke 1998). On longer time scales the return flow is likely to have left its imprint in the density field and to exhibit a depth-dependent structure that is partly reflected by the thermal wind contribution. The thermal wind contribution from Eq. (13) exhibits one main cell reaching from the Tropics to $60^{\circ} \mathrm{N}$ (Fig. 8b). Between $10^{\circ}$ and $35^{\circ} \mathrm{N}$ the cell is noisy with fluctuations occurring in small bands of latitude. The external mode exhibits two cells: a positive (clockwise) cell between $15^{\circ}$ and $35^{\circ} \mathrm{N}$ with a maximum value of $24 \mathrm{~Sv}$ and a weaker (12 Sv) negative (anticlockwise) cell between $45^{\circ}$ and $63^{\circ} \mathrm{N}$ (Fig. 8c). South of $15^{\circ} \mathrm{S}$ the 

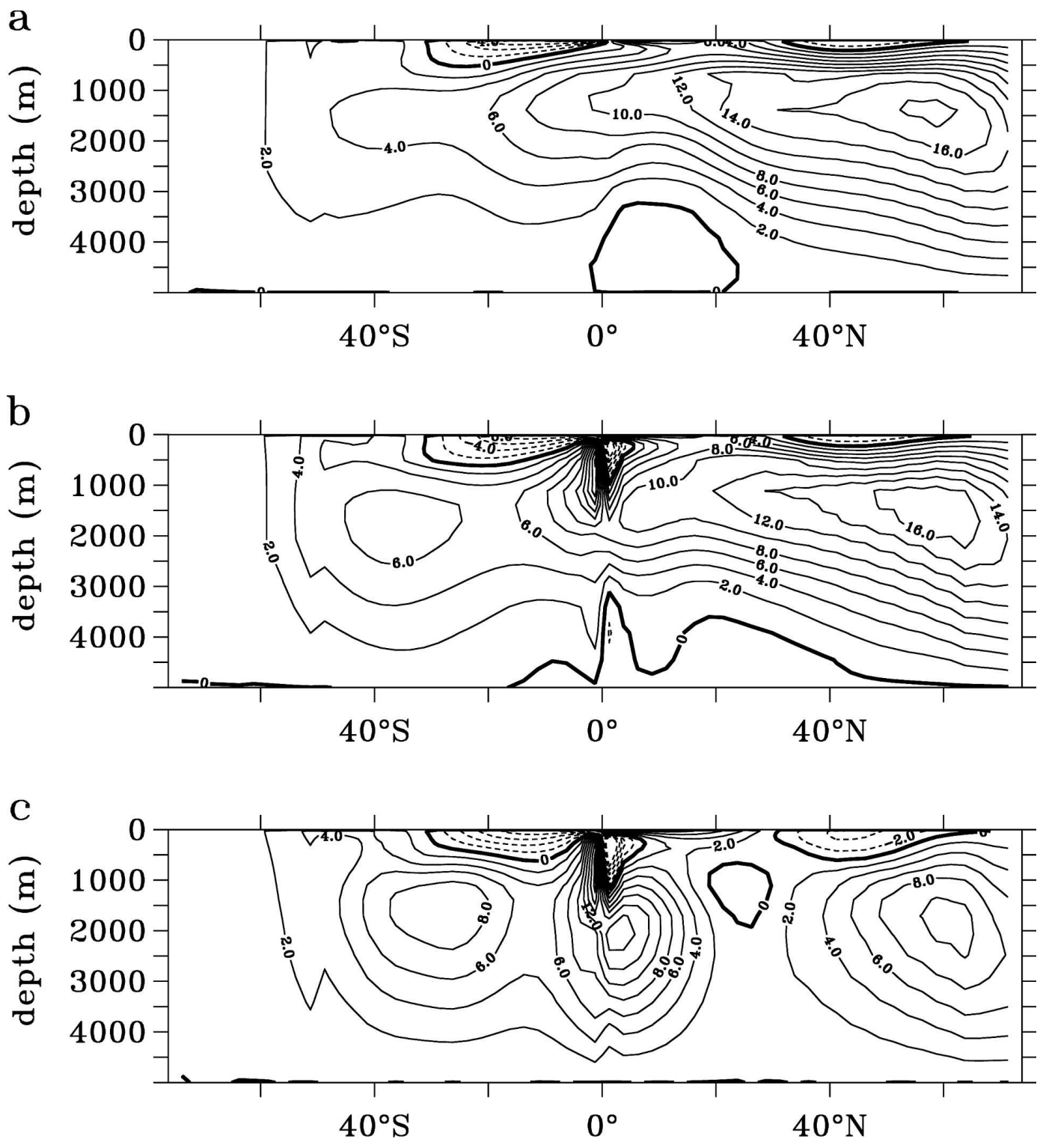

FIG. 5. Reconstruction of MOC for experiment C. (a) MOC based on meridional velocity field. (b) Sum of contributions related to the thermal wind, the Ekman transport, and the external mode [Eq. (16)]. (c) Reconstruction based on Ekman transport and thermal wind contribution [Eq. (15)]. Units are Sverdrups, and the CI $=2 \mathrm{~Sv}$.

Ekman transport is responsible for the largest northward transport. North of $35^{\circ} \mathrm{N}$ the largest contribution to the MOC is related to the thermal wind. Last, between $25^{\circ}$ and $33^{\circ} \mathrm{N}$ the external mode shows the largest transports. Note that, removing the barotropic component from the thermal wind [Eq. (14)] results in a contribution that shows a negative (anticlockwise) overturning cell between $20^{\circ}$ and $35^{\circ} \mathrm{N}$ (not shown).

For the reconstruction based on Eq. (16) the largest differences of about $4 \mathrm{~Sv}$ occur in small bands of latitude south of $35^{\circ} \mathrm{N}$ and between $45^{\circ}$ and $55^{\circ} \mathrm{N}$ at depths of around 2000 m (Fig. 9a). With Eq. (15) differences mainly occur between $45^{\circ}$ and $65^{\circ} \mathrm{N}$ and south of $20^{\circ} \mathrm{N}$ (Fig. 9b). Additionally, there is a small area of large differences around $34^{\circ} \mathrm{N}$. In contrast to experiment $\mathrm{C}$ the external mode (Fig. 8c) is not the negative image of the anomaly structure seen in Fig. 9b and large parts of the barotropic contribution to the MOC are contained in the reconstruction. This is seen between $20^{\circ}$ and $35^{\circ} \mathrm{N}$ where the differences depicted in Fig. $9 \mathrm{~b}$ are relatively small. The largest differences occur south of $15^{\circ} \mathrm{N}$ with an overestimation of more than $10 \mathrm{~Sv}$. Other areas of large anomalies are found at $33^{\circ}, 36^{\circ}$, and around $62.5^{\circ} \mathrm{N}$. As shown in Fig. 9a most of these anomalies 
a

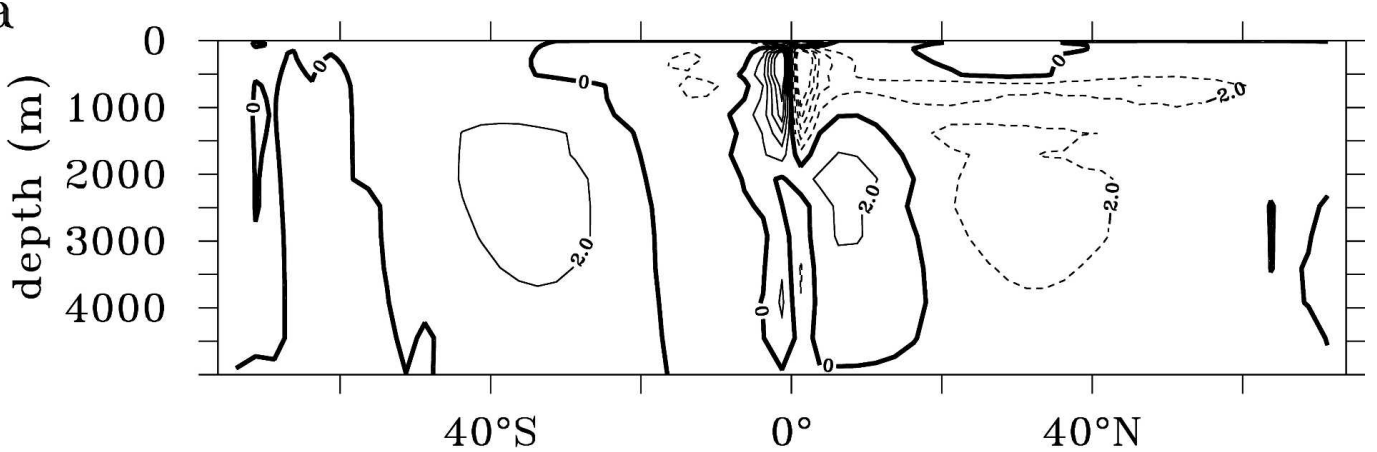

b

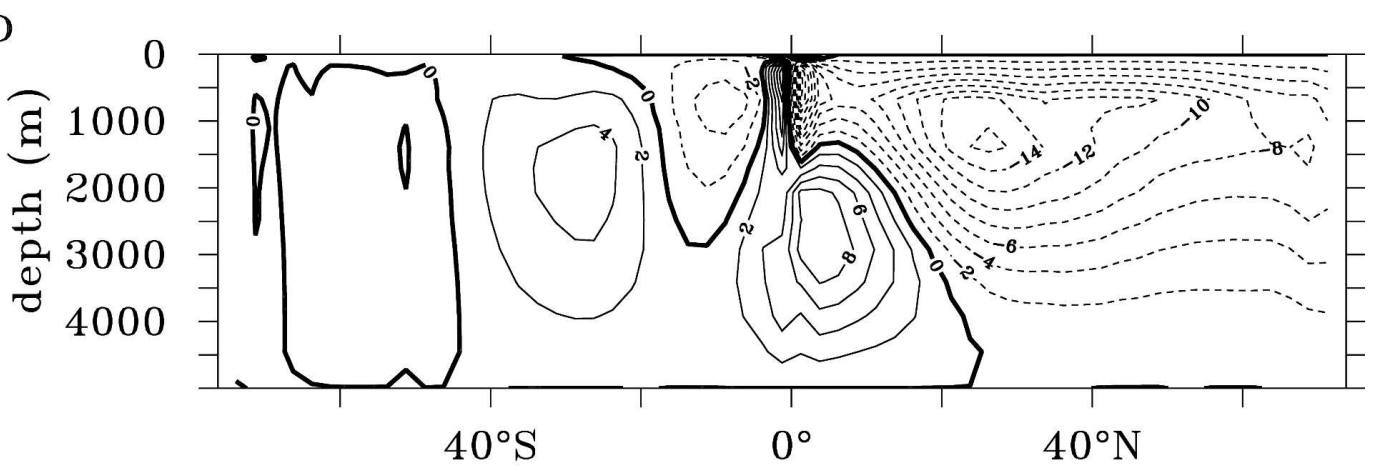

C

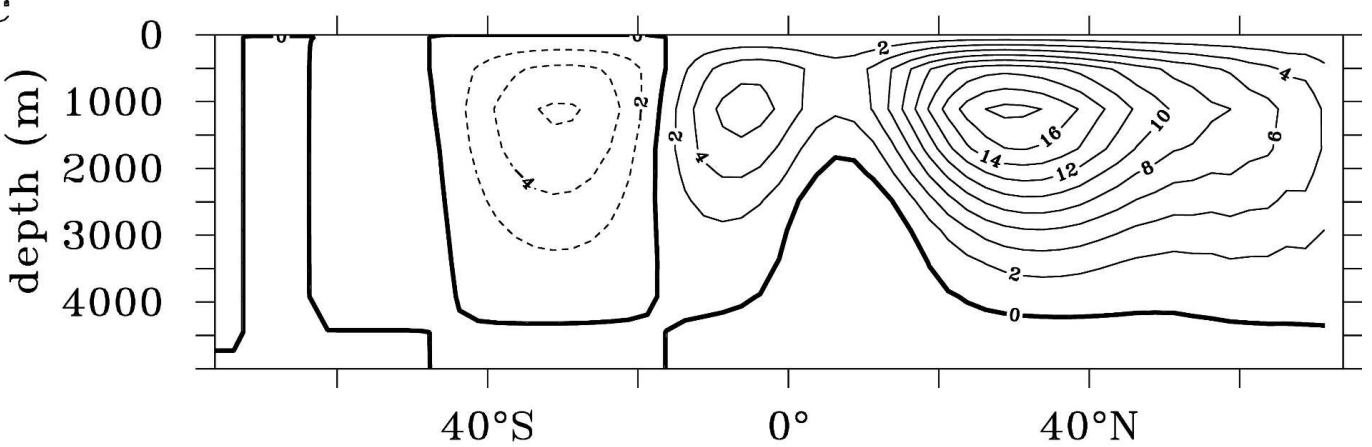

FIG. 6. Differences between estimates and MOC in experiment C. (a) Difference between the reconstruction obtained from Eq. (16) and the MOC. (b) Difference between the estimate based on Eq. (15) and the MOC. (c) External mode. Units are Sverdrups, and CI $=2 \mathrm{~Sv}$.

vanish or are reduced if the external mode is included. At first sight it might be surprising that the external mode is missed by the thermal wind in a simple model while in a more realistic case it is largely captured. The reason is that in experiment $\mathrm{C}$ large velocities are found on the basin slopes whereas the bottom velocities are generally close to zero in experiment D.

\section{Spatial and temporal MOC variability}

A principal component analysis is applied to the MOC and its reconstructions. The principal compo- nents (PCs) and the corresponding empirical orthogonal functions (EOFs) allow us to highlight the temporal (PCs) and the spatial (EOFs) variability patterns seen in the various fields.

\section{a. Idealized cases}

In the idealized cases the freshwater discharges lead to major rearrangements of the ocean circulation and the MOC basically changes from an "on" to an "off" state within a few decades. In experiment A, the leading EOFs of the MOC and of the reconstruction show 

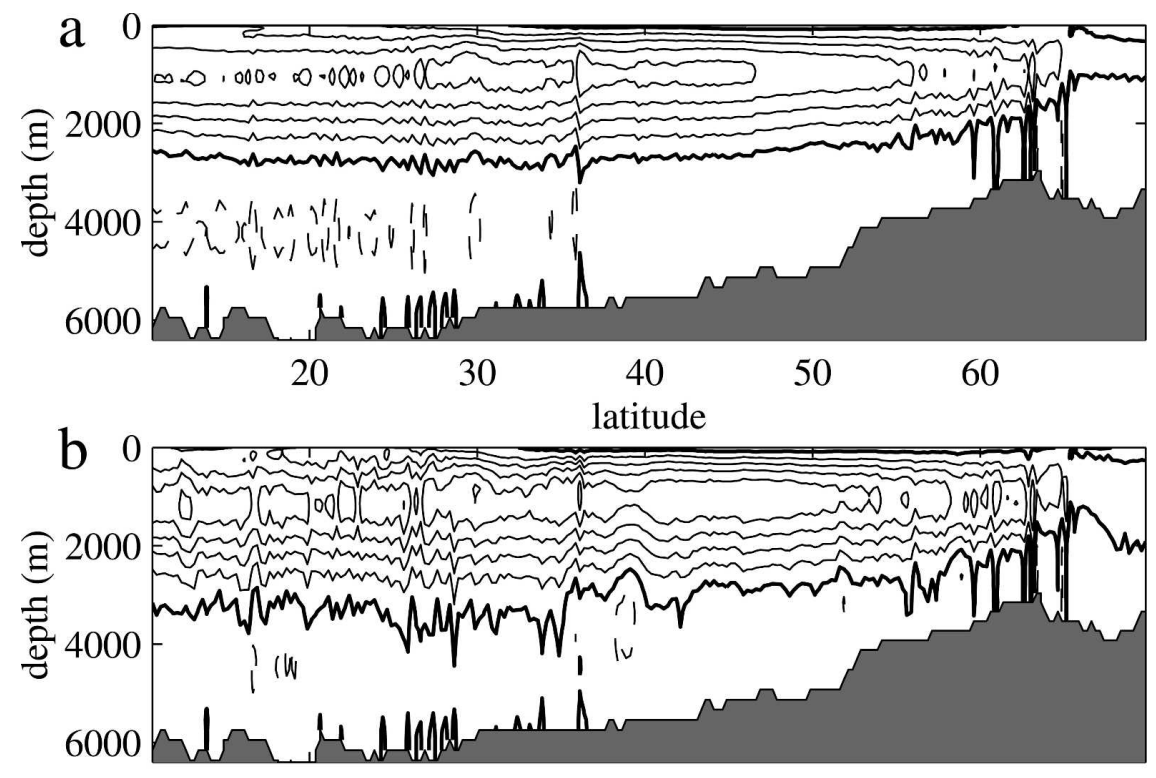

20

30

40

50

60

latitude

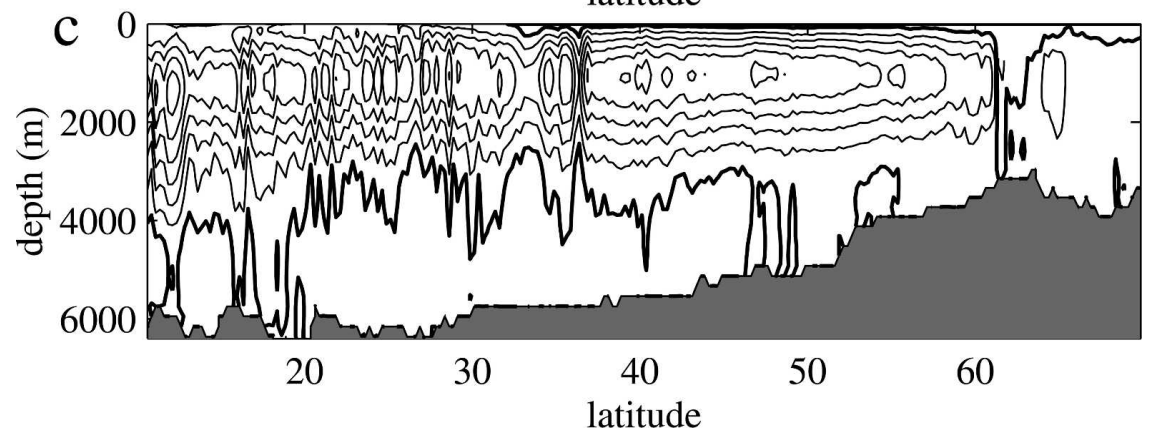

FIG. 7. Same as Fig. 5, but for reconstruction of MOC in experiment D (OCCAM). Units are Sverdrups, and the $\mathrm{CI}=4 \mathrm{~Sv}$.

the same patterns indicating a coherent weakening/ strengthening of the entire overturning cell (Figs. $10 \mathrm{a}, \mathrm{c})$. The area of largest variability centered around $50^{\circ} \mathrm{N}$ coincides with the location of maximum MOC values. The first PCs reflect the reduction of the MOC strength due to the freshwater discharge applied between years 10 and 20 (Fig. 10b). The variability explained by the first EOFs of the MOC and of the thermal wind contribution is $59 \%$ and $58 \%$ of the total variance, respectively (Fig. 10d). The second EOFs explain less than $20 \%$ in both cases. Results for experiment $\mathrm{B}$ are not shown since the addition of a (temporally) constant wind does not change the variability when compared with experiment A.

For experiment $\mathrm{C}$ the leading EOF of the MOC consists of a single-cell pattern that explains more than $75 \%$ of the variance (Fig. 11a). For the leading EOF of the reconstruction based on Eq. (15) three variability centers are found at low latitudes of the Southern
Hemisphere and at mid- and high latitudes of the Northern Hemisphere (Fig. 11b). As for the meridional mass transport, the structures seen at the equator are due to the limitation of the thermal wind balance. At midlatitudes the variability of the thermal wind contribution is confined to the upper $2000 \mathrm{~m}$. The variabilities found at greater depths for the MOC are not reproduced. For the two other centers the maximum variabilities are found at a depth of $2500 \mathrm{~m}$. The three variability centers indicate that strengthening or weakening of the thermal wind contribution at midlatitudes coincides with the opposite change at both high and low latitudes. The first PCs show a similar temporal evolution and the time series for the MOC and the thermal wind contribution can hardly be distinguished (black and light gray lines, Fig. 11e) indicating that the transient behavior of the MOC is qualitatively reflected in a reconstruction based on Eq. (15). 

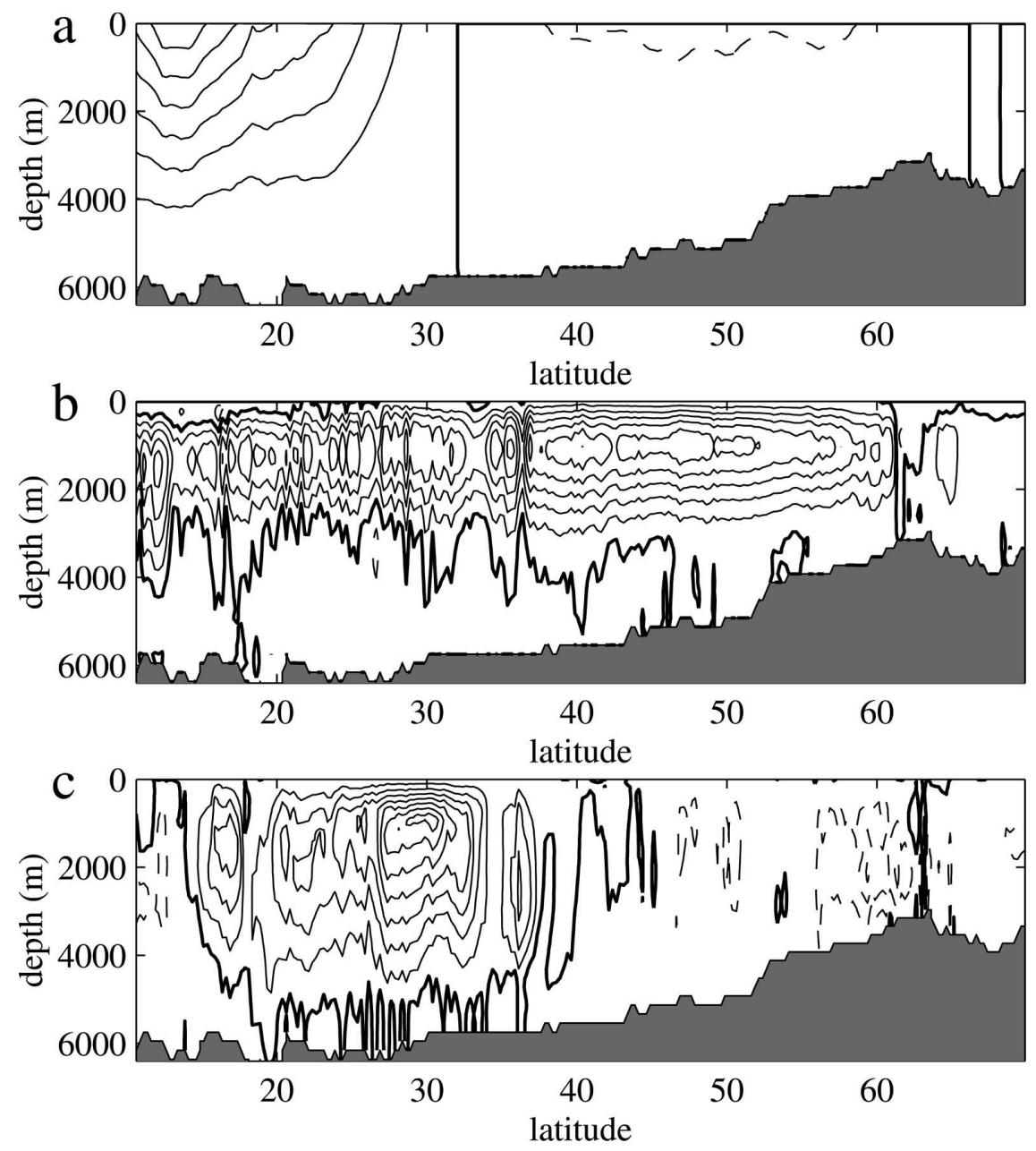

FIG. 8. Components of MOC in experiment D (OCCAM). (a) Ekman component (CI = 2 $\mathrm{Sv})$. (b) Thermal wind contribution from Eq. (15) (CI = $4 \mathrm{~Sv})$. (c) Contribution from the external mode $(\mathrm{CI}=4 \mathrm{~Sv})$.

The structure of spatial MOC variability is better captured by the external mode [Eq. (2)] even if the area of maximum variability is shifted southward relative to the MOC (Fig. 11c). Furthermore, the area of variability does not extend as far south as for the MOC. The first EOF of the external mode accounts for $50 \%$ of its total variance (Fig. 11f). Although the spatial patterns of the MOC and of the external mode are similar, the evolution of the first PCs is slightly different (Fig. 11e, dark gray dashed line).

The leading EOF of the MOC estimate obtained from Eq. (16) exhibits a "monopole" variability structure with the largest values found at high northern latitudes (Fig. 11d). The largest variability occurs at $60^{\circ} \mathrm{N}$ as seen for the MOC and the variability extends into the Southern Hemisphere. There is an almost perfect match between the PCs of the MOC and of the recon- struction. As for the MOC a large part $(70 \%)$ of the variance is explained by the leading EOF.

\section{b. Realistic model geometry}

Buoyancy forcing (heat flux, $E-P$ ) and the wind stress introduce variability in experiment $\mathrm{D}$ but there is no "on-off" change of the MOC during the model years 1985-2003. As illustrated for $45^{\circ} \mathrm{N}$ the MOC shows variability on different time scales (Fig. 12). There is a large subannual variability with peak-to-peak values of 5-10 Sv. There is also variability on interannual time scales: between 1985 and 1994 the MOC strength increases from 13 to $18 \mathrm{~Sv}$ and then gradually decreases to $14 \mathrm{~Sv}$ between 1994 and 2003.

An EOF analysis based on monthly means between 1985 and 2003 for the MOC and for its estimate obtained from Eq. (15) indicate a coherent weakening or 


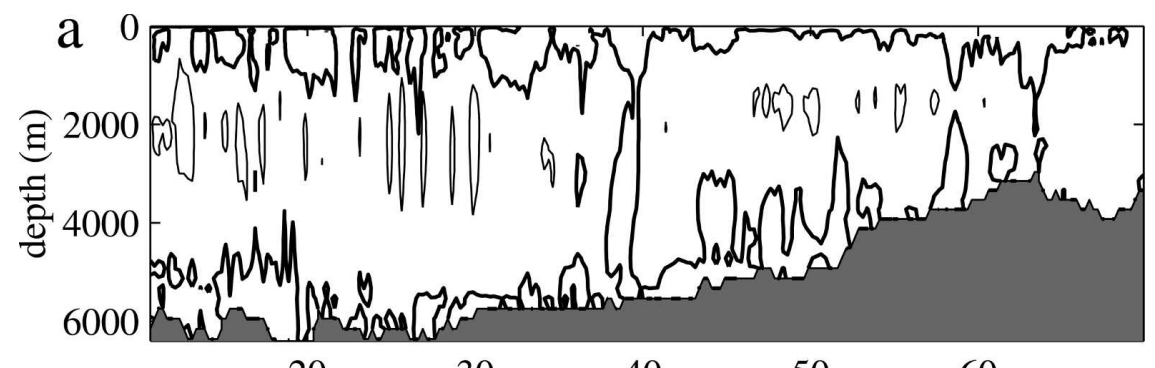

20

30

40

50

60

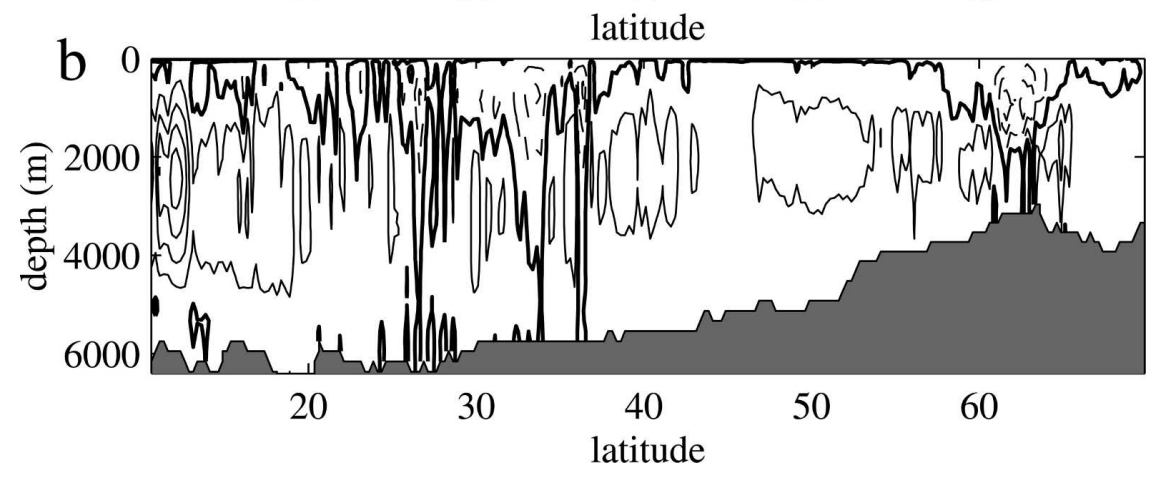

FIG. 9. Differences between estimates and MOC in experiment D. (a) Difference between the MOC and the reconstruction obtained from Eq. (16). (b) Difference between the MOC and the estimate based on Eq. (15). Units are Sverdrups, and the CI $=4$ Sv.

strengthening between $25^{\circ}$ and $60^{\circ} \mathrm{N}$ (Figs. 13a,b). The maximum variability centers are located between 1000 and 1500-m depth and occur at a shallower depth for the reconstruction than for the MOC. The largest variabilities do not occur at the ocean surface indicating that the leading mode does not just reflect the variability of the Ekman transport (which is largest at the surface), but also the changes of the density field occurring over a large depth range.

The second EOFs show a dipole structure for the MOC and the reconstruction, suggesting that a strengthening or weakening of the MOC north of $40^{\circ} \mathrm{N}$ coincides with a change of the opposite sign south of $40^{\circ} \mathrm{N}$ (Figs. 13c,d). As for the leading EOF the maximum variability of the second EOF occurs closer to the surface for the reconstruction than for the MOC. The first PCs for the MOC and the reconstruction show variability on a seasonal time scale with peaks mostly occurring during the winter months and minimum values in summer. Additionally, there is an underlying interannual variability that is seen as a gradual decrease of the PC between 1985 and 1994 followed by an increase between 1994 and 2003 (Fig. 13e, top panel). The second PC shows variability on subannual time scales but there is no clear seasonal cycle. With $8 \%-10 \%$ of explained variance the first two leading modes only account for a small fraction of the total variance. However, the structure of the scree graph for the first seven
EOFs is similar for the MOC and the reconstruction thus suggesting a similar structure for the higher modes as well (Fig. 13f).

Looking at the leading modes for the thermal wind and Ekman components separately, allows us to highlight the variability caused by the wind stress or by the density field (Fig. 14). The first EOF for the thermal wind contribution shows an area of maximum variability between $40^{\circ}$ and $60^{\circ} \mathrm{N}$ (Fig. 14a). For the leading EOF of the Ekman transport the variability area between $30^{\circ}$ and $60^{\circ} \mathrm{N}$ coincides with the location of the anticlockwise Ekman cell shown in Fig. 8. From the PCs it becomes clear that the seasonal signal previously seen for the MOC and the reconstruction is mostly due to the wind: the first PC of the Ekman contribution is similar to the signal seen in Fig. 13e. For the first PC of the thermal wind the strongest signal occurs on an interannual time scale and reflects the long-term changes seen in Fig. 13e. The leading EOF shown in Fig. 13b is a combination of the leading modes of the thermal wind and Ekman contributions (Figs. 14a,b).

For the second EOFs the thermal wind as well as the Ekman component exhibit variability on subannual time scales (Fig. 14f). The spatial variability patterns show that most variability is found south of $35^{\circ} \mathrm{N}$ for the thermal wind contribution (Fig. 14c) and a dipole structure characterizes the variability pattern of the Ekman contribution. The pattern of the second EOF seen in 
a

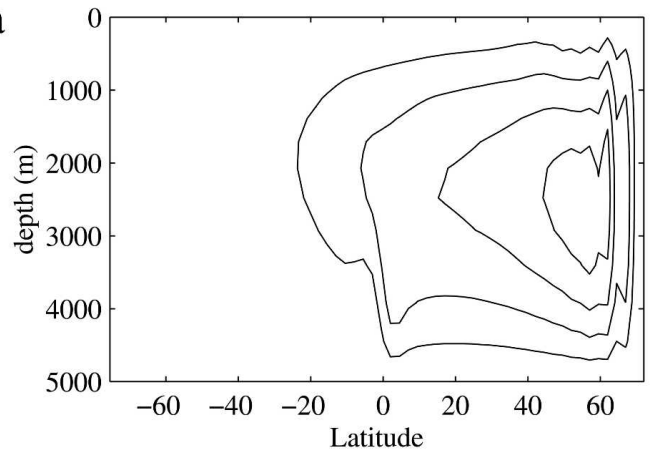

c

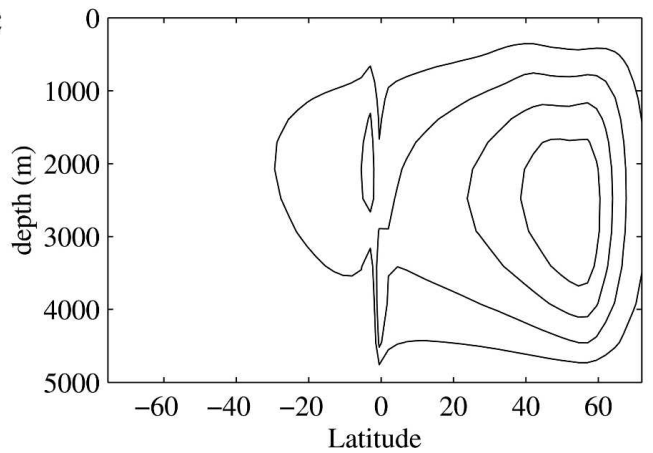

b

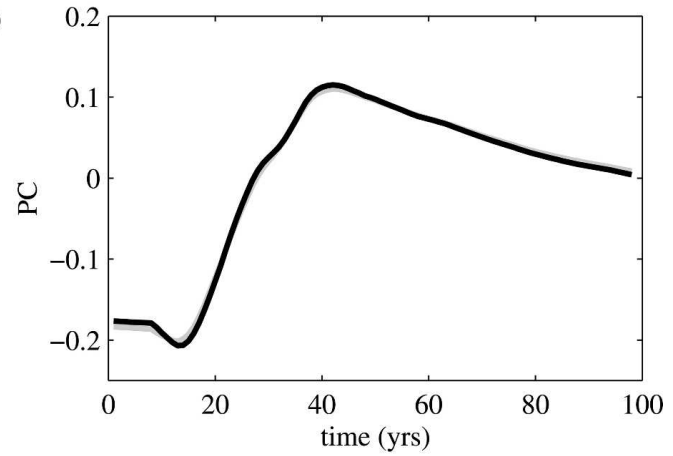

d

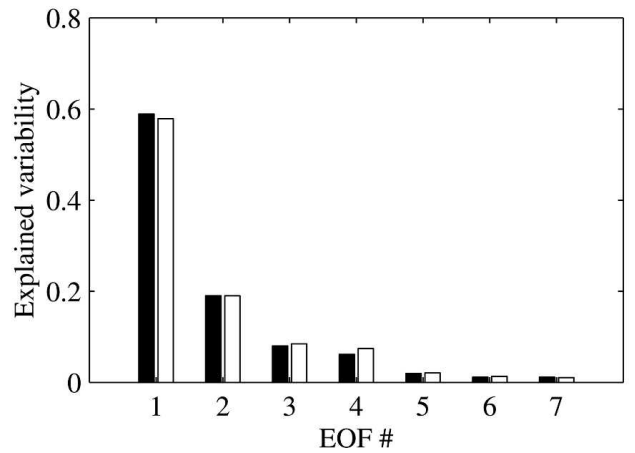

FIG. 10. (a) Normalized leading EOF of the meridional overturning for experiment A. (b) Leading EOF of the thermal wind contribution. (c) First PCs for the meridional overturning (black) and the thermal wind contribution (gray). (d) Variance explained by the first seven EOFs of the meridional overturning (black bars) and of the thermal wind contribution (white bars).

Fig. 13d appears to be a combination of the spatial patterns shown in Figs. 14c,d: the variability occurring between $50^{\circ}$ and $60^{\circ} \mathrm{N}$ reflects the wind while the variability centered at $34^{\circ} \mathrm{N}$ is found in the thermal wind.

If annual means are used the EOF patterns show a single cell structure for the $\mathrm{MOC}$ and its reconstruction (Figs. 15a,b). The largest difference between the leading EOFs of the MOC and of its estimate occur south of $30^{\circ} \mathrm{N}$, where larger variabilities are found for the MOC. As for the monthly means the maximum variability does not occur at the surface but instead is found at depths between 1500 and $2500 \mathrm{~m}$ indicating rearrangements of the circulation involving a large fraction of the water column. The leading modes have similar temporal evolutions (Fig. 15c) and they explain about $25 \%$ of the total variance for both the MOC and its estimate (Fig. 15d). The second modes still explain between 15\% and $20 \%$ but in contrast to the monthly means neither the corresponding EOFs nor the principal components show similar spatial and temporal patterns (not shown).

Confining the EOF analysis based on annual means to the northern part of the model domain increases the dominance of the leading EOF (Fig. 16) and 35\% of the total variance is explained by the leading mode between $40^{\circ}$ and $65^{\circ} \mathrm{N}$ (Fig. 16f). The variability patterns seen for the MOC or the reconstruction are mainly due to changes reflected in the boundary density field. The leading EOF of the thermal wind contribution according to Eq. (13) depicted in Fig. 16c shows that the spatial variability pattern is almost identical to that obtained for the sum of the thermal wind and Ekman contributions [Eq. (15)]. In contrast, the pattern related to the first EOF of the Ekman contribution (Fig. 16d) has a different spatial structure with the largest variability occurring at the surface and a gradual decrease with depth.

The temporal evolutions of the first PCs for the MOC, the reconstruction from Eq. (15), and the thermal wind contribution from Eq. (13) are almost identical. The different MOC trends seen from 1985 to 1994 and from 1994 to 2003 (Fig. 12) are reflected in the temporal evolution of the PCs. This evolution is not captured by the first PC of the Ekman contribution, which has a more pronounced short-term variability. The leading modes of the thermal wind and Ekman contributions explain $40 \%$ and $55 \%$ of the total variance.

\section{Outlook}

In the model using realistic topography the main modes of variability are explained by the thermal wind and Ekman contributions. If we use monthly means the 

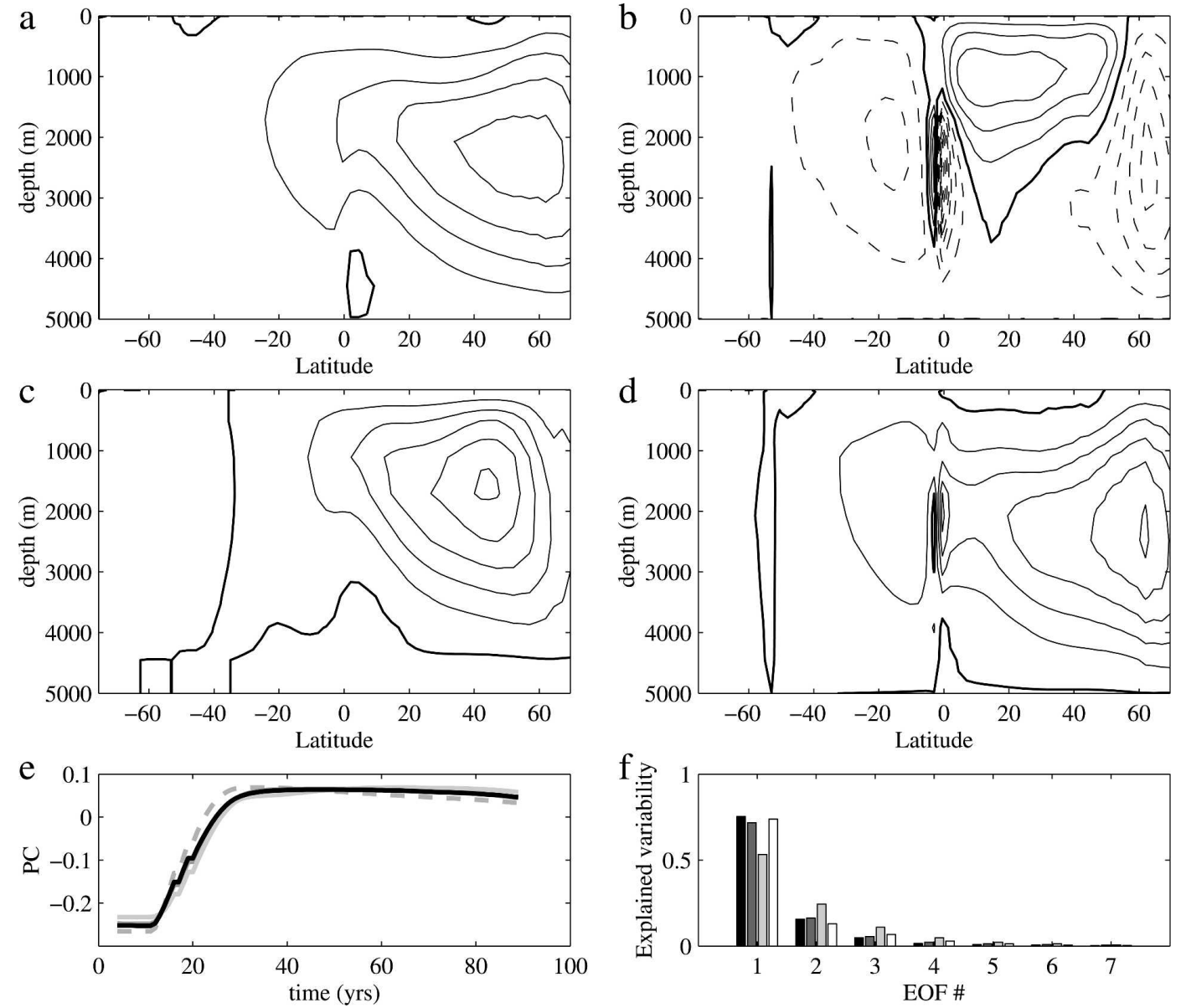

FIG. 11. Spatial and temporal variability in experiment C. (a) Normalized leading EOF of meridional overturning. (b) Leading EOF for the MOC reconstruction based on Eq. (15). (c) Leading EOF of the external mode. (d) Leading EOF for the MOC reconstruction based on Eq. (16). (e) First PCs for MOC (black), external mode (dark gray, dashed), thermal wind (light gray), and the sum of all components (dark gray). (f) Variance explained by the first seven EOFs of the MOC (black), the external mode (light gray), and the reconstructions based on Eqs. (15) and (16) (dark gray and white bars, respectively).

dominant variability is a seasonal signal that mainly reflects the variability of the wind field. However, the temporal variability related to the second EOF (explaining almost the same amount of variability as the first EOF) occurs on subannual time scales for both the thermal wind and the Ekman contributions. Most of the interannual variability found in the thermal wind contribution occurs north of $40^{\circ} \mathrm{N}$ whereas the shortterm variability seems confined south of $35^{\circ} \mathrm{N}$ (Figs. $14 \mathrm{a}, \mathrm{c})$. The fact that the thermal wind contribution exhibits short-term variability that is not confined to the surface ocean (Fig. 14c) is interesting because it raises the following question: what processes can modify a substantial part of the water column and the related meridional mass transport on short time scales? An analysis of these processes is beyond the scope of the present paper but it is certainly an area that de- serves some attention especially on the background of funded MOC monitoring projects (e.g., Marotzke et al. 2002).

Another aspect of this study is that the information needed to calculate the thermal wind contribution could be obtained from sea sediments along the continental slope. This is of particular interest if one consid-

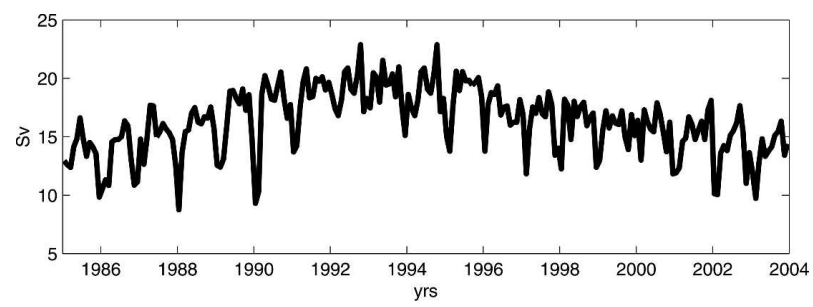

FIG. 12. MOC at $45^{\circ} \mathrm{N}$ at $1000-\mathrm{m}$ depth for experiment D. 

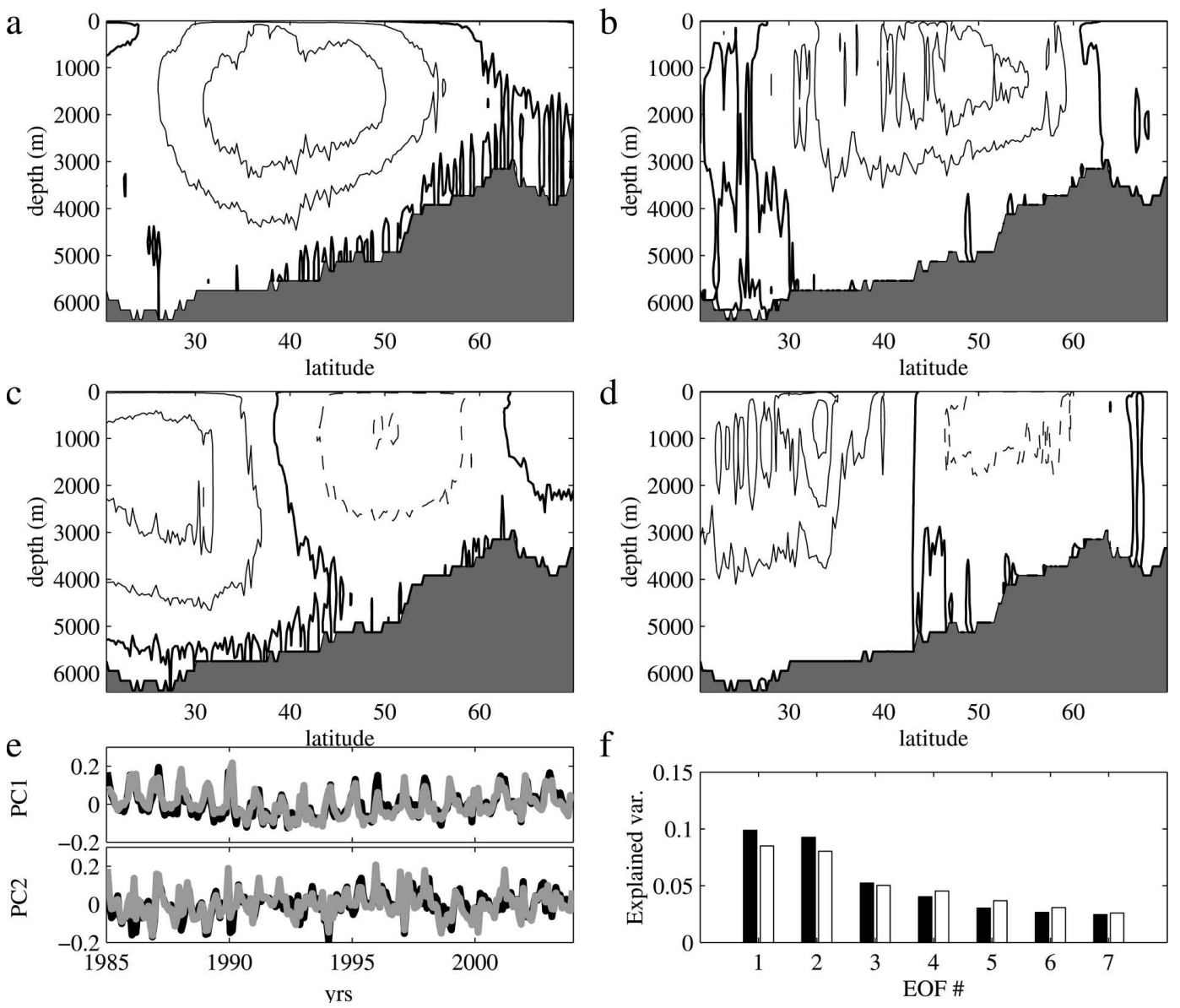

FIG. 13. Spatial and temporal variability based on monthly means for experiment D. (a) Leading EOF for the MOC. (b) Leading EOF for the MOC reconstruction based on the Ekman and thermal wind contributions [Eq. (15)]. (c) Second EOF of the MOC. (d) Second EOF of the MOC reconstruction based on Eq. (15). (e) (top) First PC for the MOC (black line) and its reconstruction (gray line). (bottom) Second PC for the MOC (black line) and its reconstruction (gray line). (f) Variance explained by the first 7 EOFs of the MOC (black bars) and its estimate (white bars).

ers past ocean circulations. Information about the strength of the wind stress is not easily available but past seawater densities have left their imprint in sea sediments (Lynch-Stieglitz et al. 1999; Lynch-Stieglitz 2001). The work presented here is based on simple assumptions: the marginal densities are assumed to be known everywhere at all times and no errors in the density value have been taken into account. In reality the calcite shells of foraminifera needed to estimate past water densities are not preserved everywhere. In a refined model study the amount of density information that is assumed to be known could be reduced and an error comparable to that of seawater density obtained from measurements (of seawater/sea sediments) could be added to the model densities. This would help to address the question if a reliable picture of the MOC can still be obtained with sparse data that are subject to uncertainties.

\section{Conclusions}

Based on the analysis of the results obtained from a hierarchy of numerical models we conclude the following:

1) In idealized model setups without topography the knowledge of boundary densities and of the zonal wind stress is sufficient to reproduce most of the strength and variability of the full MOC cell.

2) A large part of the meridional flow (resulting from the external mode) is not reflected in the boundary densities if gradually sloping sidewalls are added. Only the temporal MOC variability can be reconstructed well in this case.

3) Shortcomings in the MOC reconstruction are linked to the assumption of small bottom velocities for the thermal wind contribution. At locations where large bottom velocities are found over sloping topogra- 

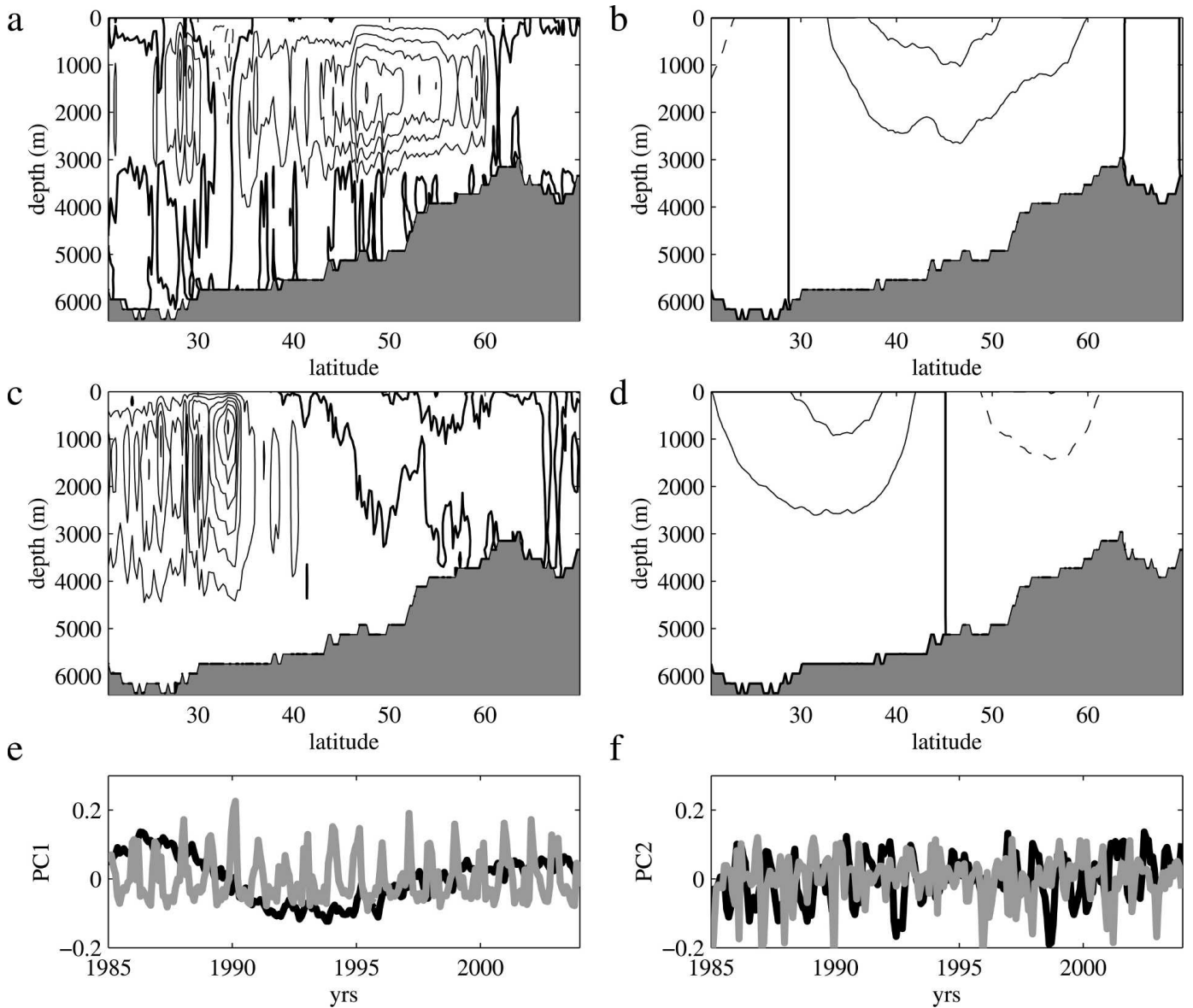

FIG. 14. Spatial and temporal variability based on monthly means for experiment D. (a) Leading EOF for the thermal wind contribution based on Eq. (13). (b) Leading EOF for the Ekman contributions. (c) Second EOF of the thermal wind contribution. (d) Second EOF of the Ekman contribution. (e) First PC for the thermal wind and Ekman contributions (black and gray lines, respectively). (f) Second PC for the thermal wind and Ekman contributions (black and gray lines, respectively).

phy, the projection of the external mode on the MOC is not reproduced.

4) In an eddy-permitting model with realistic topography, boundary densities and the zonal wind stress allow us to reproduce the mean $\mathrm{MOC}$ as well as the leading modes of variability.

5) On seasonal time scales the Ekman contribution accounts for most of the variability but short-term variability is also found in the thermal wind contribution. On interannual time scales the thermal wind contribution (i.e., the boundary density) reflects most of the MOC variability.

Acknowledgments. We thank Beverly de Cuevas and Andrew Coward for their help with the OCCAM model. We also thank Olivier Marchal, Harry Bryden, and two anonymous reviewers for their useful comments. This work was supported by the National
Environment Research Council (NERC) as part of the RAPID Programme and by the University of Southampton.

\section{APPENDIX A}

\section{Equivalence of Mass-Conserving Barotropic Velocity Corrections in the Absence of Topography}

The integration of Eqs. (13) and (14) over the full ocean depth can be written as

$$
\begin{gathered}
\int_{0}^{L} d x \int_{-H}^{0} \tilde{v} d z-\int_{0}^{L} d x \int_{-H}^{0} \hat{v} d z=0 \text { and } \\
\int_{0}^{L} d x \int_{-H}^{0} \tilde{v} d z-\int_{0}^{L} d x \int_{-H}^{0} \bar{v}^{\prime} d z=0,
\end{gathered}
$$



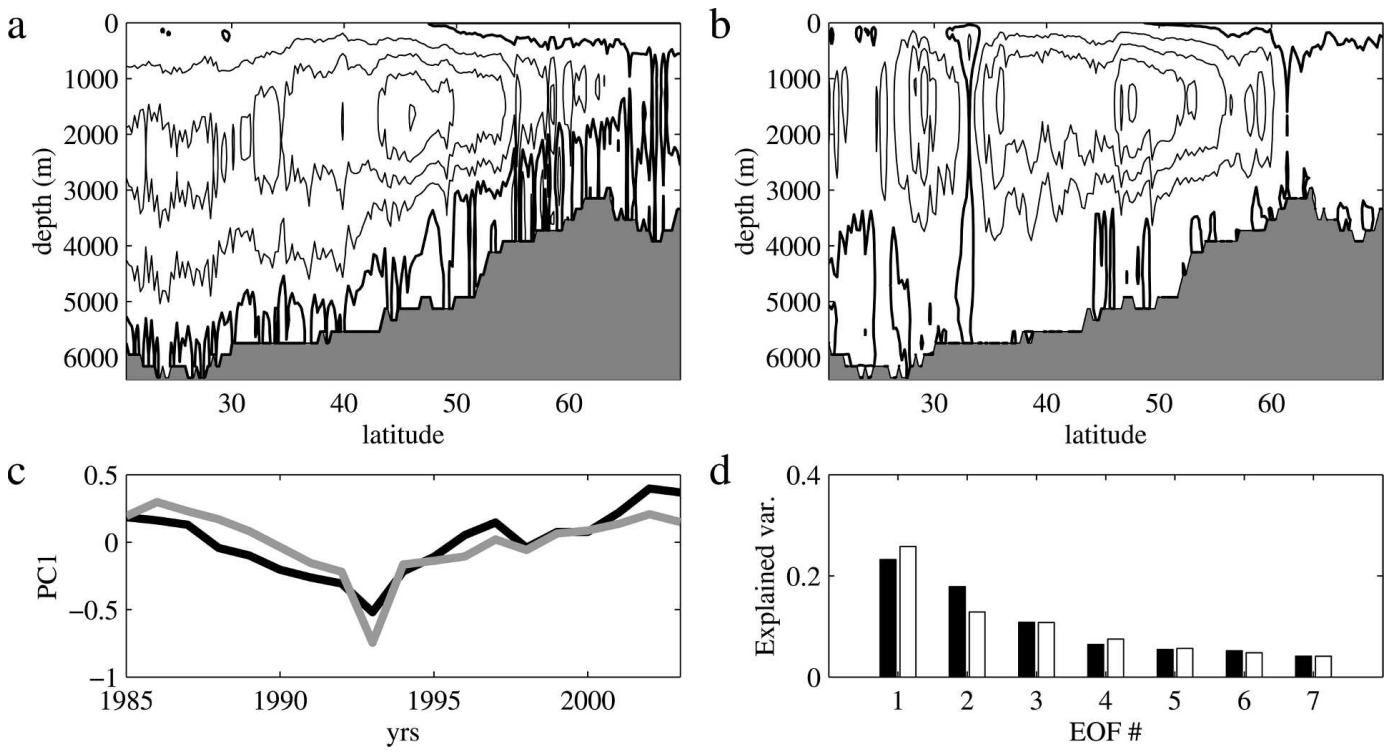

FIG. 15. Spatial and temporal variability based on annual means for experiment D. (a) Leading EOF for the MOC. (b) Leading EOF for the MOC reconstruction based on the Ekman and thermal wind contributions [Eq. (15)]. (c) First PC for the MOC (black line) and its reconstruction (gray line). (d) Variance explained by the first 7 EOFs of the MOC (black bars) and its estimate (white bars).

where $L$ is the depth-independent basin width and $H$ is the zonally constant ocean depth. The second terms of Eqs. (A1) and (A2) must have the same value. Inverting the order of integrations yields

$$
\int_{-H}^{0} d z \int_{0}^{L} \hat{v} d x=\int_{-H}^{0} d z \int_{0}^{L} \bar{v}^{\prime} d x
$$

Since $\hat{v}$ and $\bar{v}^{\prime}$ are depth-independent (barotropic) velocity fields,

$$
\frac{\partial \hat{v}(x)}{\partial z}=\frac{\partial \bar{v}(x)^{\prime}}{\partial z}=0
$$

is fulfilled at all longitudes and depths. For a rectangular longitude-depth section (no topography) this means that the zonal integral of $\hat{v}$ and $\bar{v}^{\prime}$ is constant with depth as well:

$$
\frac{\partial \int_{0}^{L} \hat{v}(x) d x}{\partial z}=\frac{\partial \int_{0}^{L} \bar{v}(x)^{\prime} d x}{\partial z}=0 .
$$

Since the barotropic velocity corrections $\hat{v}$ and $\bar{v}^{\prime}$ must both ensure mass balance across the section, their zonal integrals

$$
\int_{0}^{L} \hat{v}(z, x) d x=\int_{0}^{L} \bar{v}^{\prime}(z, x) d x=\text { const }
$$

are identical for all depths $z$. This not only holds true for the velocity corrections $\hat{v}$ and $\bar{v}^{\prime}$ but for any baro- tropic correction field, regardless of its zonal structure. As long as a zero net mass transport across the section is ensured, the result for the thermal wind contributions defined in Eqs. (13) and (14) is the same.

\section{APPENDIX B}

\section{Thermal Wind Contribution Based on Boundary Densities or on the Full Density Field}

As mentioned in section 2, calculating the thermal wind contribution based on boundary densities only is equivalent to using the full density field. Based on the thermal wind relation the shear of the flow can be computed for the entire section and the streamfunction $\tilde{\psi}$ can be written as

$$
\tilde{\psi}=\int_{-H}^{z^{\prime}} d z \int_{x_{w}}^{x_{e}} d x \int_{-H}^{z^{\prime}} \frac{\partial v}{\partial z} d z .
$$

Inverting the order of the second and the third integration and making use of Eq. (8) yields

$$
\tilde{\psi}=-\frac{g}{f \rho^{*}} \int_{-H}^{z^{\prime}} d z \int_{-H}^{z^{\prime}} \rho_{e}-\rho_{w} .
$$

This can be written as

$$
\tilde{\psi}=-\frac{g}{f \rho^{*}} \int_{-H}^{z^{\prime}} d z \int_{x_{w}}^{x_{e}} d x \int_{-H}^{z^{\prime}} \frac{1}{L\left(z^{\prime}\right)}\left(\rho_{e}-\rho_{w}\right) d z .
$$



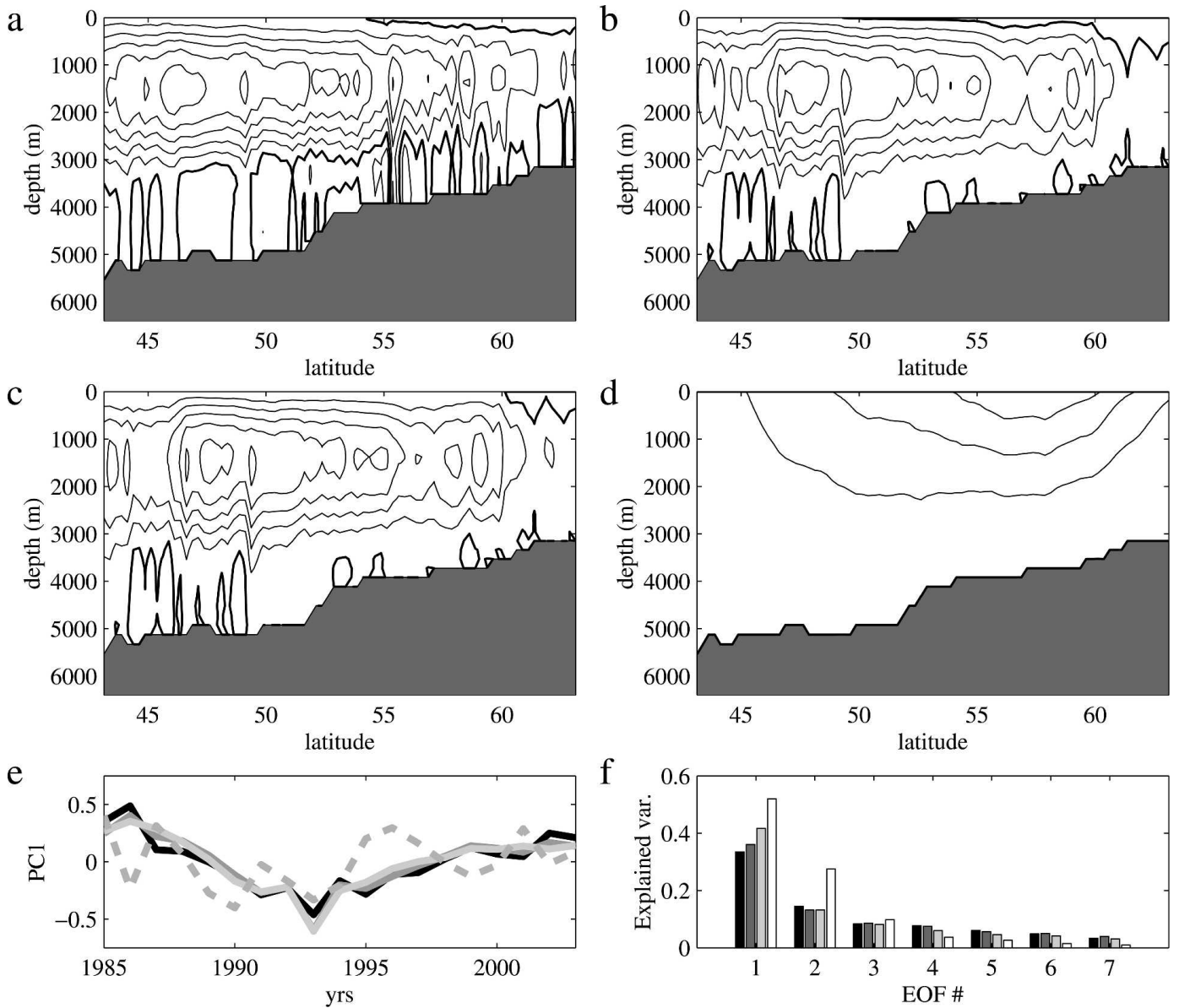

FIG. 16. Spatial and temporal variability between $40^{\circ}$ and $70^{\circ} \mathrm{N}$ based on annual means for experiment D. (a) Leading EOF for the MOC. (b) Leading EOF for the MOC reconstruction based on the Ekman and thermal wind contributions [Eq. (15)]. (c) Leading EOF for the thermal wind contribution. (d) Leading EOF for the Ekman contribution. (e) First PC for the MOC (black line), its reconstruction based on Eq. (15) (dark gray line), the thermal wind component (light gray line), and the Ekman component (dashed). (f) Variance explained by the first 7 EOFs of the MOC (black bars), its estimate (dark gray bars), the thermal wind component (light gray bars), and the Ekman component (white bars).

According to Eq. (9) this is equivalent to

$$
\bar{\psi}=\int_{-H}^{z^{\prime}} d z \int_{x_{w}}^{x_{e}} \tilde{v}
$$

which corresponds to Eq. (11).

\section{REFERENCES}

Baehr, J., J. Hirschi, J.-O. Beismann, and J. Marotzke, 2004: Monitoring the meridional overturning circulation in the North Atlantic: A model-based array design study. J. Mar. Res., 62, 283-312.

Broecker, W. S., G. Bond, M. Klas, E. Clark, and J. McManus, 1992: Origin of the northern Atlantic's Heinrich events. Climate Dyn., 6, 265-273.

Coachman, L. K., and K. Aagaard, 1988: Transports through Bering Strait and interannual variability. J. Geophys. Res., 93, $15535-15539$.
Collins, M., T. F. B. Tett, and C. Cooper, 2001: The internal climate variability of HadCM3, a version of the Hadley Centre coupled model without flux adjustments. Climate Dyn., 17, 66-81.

Cubasch, U., and Coauthors, 2001: Projections of future climate change. Climate Change 2001: The Scientific Basis, J. T. Houghton et al., Eds., Cambridge University Press, 525-582.

Dansgaard, W., and Coauthors, 1993: Evidence for general instability of past climate from a $250-\mathrm{kyr}$ ice-core record. Nature, 364, 218-220.

Delworth, T., S. Manabe, and R. J. Stouffer, 1993: Interdecadal variations of the thermohaline circulation in a coupled ocean-atmosphere model. J. Climate, 6, 1993-2011.

Dickson, R. R., and J. Brown, 1994: The production of North Atlantic Deep Water: Sources, rates, and pathways. J. Geophys. Res., 99, 12 319-12 341.

Eden, C., and R. J. Greatbatch, 2003: A damped oscillation in the North Atlantic climate system. J. Climate, 16, 4043-4060.

Ganachaud, A., and C. Wunsch, 2000: Improved estimates of 
global ocean circulation, heat transport and mixing from hydrographic data. Nature, 408, 453-457.

Ganopolski, A., and S. Rahmstorf, 2001: Rapid changes of glacial climate simulated in a coupled climate model. Nature, 409, $153-158$.

Häkkinen, S., 1999: Variability of the simulated meridional heat transport in the North Atlantic for the period 1951-1993. J. Geophys. Res., 104, 10 991-11 007.

Hall, M. M., and H. L. Bryden, 1982: Direct estimates and mechanisms of ocean heat transport. Deep-Sea Res., 29, 339-359.

Heinrich, H., 1988: Origin and consequences of cyclic ice rafting in the Northeast Atlantic Ocean during the past 130,000 years. Quat. Res., 29, 142-152.

Hirschi, J., and T. F. Stocker, 2002: Rapid changes of the oceanic circulation in a hierarchy of ocean models. Tellus, 54A, 273287.

— J. Jaehr, J. Marotzke, J. Stark, S. Cunningham, and J.-O. Beismann, 2003: A monitoring design for the Atlantic meridional overturning. Geophys. Res. Lett., 30, 1413-1416.

Kalnay, E., and Coauthors, 1996: The NCEP/NCAR 40-Year Reanalysis Project. Bull. Amer. Meteor. Soc., 77, 437-495.

Lang, C., M. Leuenberger, J. Schwander, and S. Johnsen, 1999: $16^{\circ} \mathrm{C}$ rapid temperature variation in Central Greenland 70,000 years ago. Science, 286, 934-937.

Lee, T., and J. Marotzke, 1998: Seasonal cycles of meridional overturning and heat transport of the Indian Ocean. J. Phys. Oceanogr., 28, 923-943.

Lee, T. N., W. E. Johns, R. J. Zantopp, and E. R. Fillenbaum, 1996: Moored observations of western boundary current variability and thermohaline circulation at $26.5^{\circ} \mathrm{N}$ in the subtropical North Atlantic. J. Phys. Oceanogr., 26, 962-983.

Levitus, S., and T. Boyer, 1994: Temperature. Vol. 4, World Ocean Atlas 1994, NOAA Atlas NESDIS 4, 117 pp.

Lynch-Stieglitz, J., 2001: Using ocean margin density to constrain ocean circulation and surface wind strength in the past. Geochem. Geophys. Geosyst., 2, doi:10.1029/2001GC000208.
—, W. B. Curry, and N. Slowey, 1999: Weaker Gulf Stream in the Florida Straits during the Last Glacial Maximum. Nature, 402, 644-648.

Marotzke, J., 1997: Boundary mixing and the dynamics of threedimensional thermohaline circulations. J. Phys. Oceanogr., 27, 1713-1728.

_, R. Giering, K. Q. Zhang, D. Stammer, C. Hill, and T. Lee, 1999: Construction of the adjoint MIT ocean general circulation model and application to Atlantic heat transport sensitivity. J. Geophys. Res., 104, 29 529-29 547.

- S. A. Cunningham, and H. L. Bryden, 2002: Monitoring the Atlantic meridional overturning circulation at $26.5^{\circ} \mathrm{N}$. [Available online at http://www.soton.ac.uk/rapidmoc.]

Marsh, R., B. A. de Cuevas, A. C. Coward, H. L. Bryden, and M. Álvarez, 2005a: Thermohaline circulation at three key sections in the North Atlantic over 1985-2002. Geophys. Res. Lett., 32, L10604, doi:10.1029/2004GL022281.

,,,--- A. J. G. Nurser, and S. A. Josey, 2005b: Water mass transformation in the North Atlantic over 1985-2002 simulated in an eddy-permitting model. Ocean Sci. Discuss., 1, 127-144.

Marshall, J., A. Adcroft, C. Hill, L. Perelman, and C. Heisey, 1997: A finite-volume, incompressible Navier-Stokes model for studies of the ocean on parallel computers. J. Geophys. Res., 102, 5753-5766.

Petit, J. R., and Coauthors, 1999: Climate and atmospheric history of the past 420,000 years from the Vostok ice core, Antarctica. Nature, 399, 429-436.

Trenberth, K. E., and A. Solomon, 1994: The global heat balance: Heat transports in the atmosphere and ocean. Climate Dyn., 10, 107-134.

_ and J. M. Caron, 2001: Estimates of meridional atmosphere and ocean heat transports. J. Climate, 14, 3433-3443.

Weaver, A. J., and E. S. Sarachik, 1991: Evidence for decadal variability in an ocean general circulation model: An advective mechanism. Atmos.-Ocean, 29, 197-231. 